\title{
Evaluation of Chemical-Kinetics Models for n-Heptane Combustion Using a Multidimensional CFD Code
}

\author{
Viswanath R. Katta* \\ Innovative Scientific Solutions, Inc., Dayton, OH, 45440
}

Suresh K. Aggarwal

Department of Mechanical Engineering, University of Illinois at Chicago, Chicago, IL

and

William M. Roquemore

Propulsion Directorate, Wright-Patterson Air Force Base, OH, 45433

Submitted to AIAA Journal

*Corresponding Author: vrkatta@gmail.com 


\begin{abstract}
:
Computational fluid dynamics (CFD)-based predictions are presented for nonpremixed and partially premixed flames burning vaporized n-heptane fuel. Three state-of-the-art chemical kinetics models are incorporated into a time-dependent, two-dimensional, CFD model known as UNICORN. The first mechanism is the San Diego (SD) mechanism (52 species and 544 reactions), the second one is the Lawrence Livermore National Laboratory (LLNL) mechanism (160 species and 1540 reactions), and the third one is the National Institute of Standards and Technology (NIST) mechanism (197 species and 2926 reactions). Soot model based on acetylene, and radiation model based on optically thin media assumption are included. Twodimensional calculations are made for the detailed structures of nonpremixed and partially premixed flames, strain-induced extinction and diffusion-controlled autoignition and the results are compared with the available experimental data. Diffusion-controlled autoignition characteristics are also compared with the ignition delay times calculated in homogeneous stoichiometric mixture of n-heptane and air. Through the simulation of complete flowfields between the opposing fuel and air ducts reasons for the flame curvature seen in some experiments are explained. Compared to the traditional one-dimensional models for opposing-jet flames, two-dimensional simulations are found to give results closer to the experimental values when the flames are highly stretched. While LLNL mechanism predicted extinction of a nonpremixed flame better, NIST mechanism predicted the autoignition behavior in the flowfield established by the opposing jets of fuel and heated air better. However, all three mechanisms predicted both the nonpremixed and partially premixed n-heptane flames very well. Surprisingly, SD mechanism with less than one-third of the species used in the other two mechanisms predicted flame structures with nearly the same accuracy. Comparisons made with the available experimental data could not suggest which mechanism is better in predicting the minor species concentrations. Computations also could not predict the temperature rise detected in the experiments in the premixed-combustion zone of a partially premixed flame when it was subjected to a moderately high stretch rate.
\end{abstract}




\section{Introduction:}

Detailed chemical kinetics for describing combustion of hydrocarbon fuels involves several hundred species and several thousand elementary reactions. The need for more accurate and presumably larger chemical-kinetic mechanism is being strongly driven by the escalating costs of petroleum-based fuels and the search for alternate and renewable fuels. Significant progress has been reported in recent years in the development of detailed reaction mechanisms for simple as well as complex hydrocarbon fuels. A considerable part of this effort has focused on the oxidation chemistry of methane $\left(\mathrm{CH}_{4}\right)$ and n-heptane $\left(\mathrm{n}-\mathrm{C}_{7} \mathrm{H}_{16}\right)$, as these two fuels are considered as the most representative gaseous and liquid fuels, respectively. Moreover, methane is the dominant constituent of natural gas, while n-heptane is a primary reference fuel for octane rating in internal combustion engines, and also a good surrogate for gasoline [1,2] and diesel [3,4] fuels. Consequently, several detailed mechanisms have been developed and validated for these two fuels. The mechanisms for methane oxidation include GRI-3.0 [5], HPNGB-1 [6], and Curran [7] mechanisms. Similarly, several detailed reaction mechanisms have been reported for n-heptane oxidation [8-10].

Detailed chemical-kinetics mechanisms for fuels are generally validated using some specific targets, such as flow reactor data, ignition delay times from shock tube experiments, and laminar flame speeds. The validation process then involves performing zero- and one-dimensional simulations using codes such as RUN1DL [11], OPPDIF [12], and CHEMKIN [13] and comparing the results with the available experimental data. Extensive experimental data for the intermediate species concentrations are required for obtaining a reasonably built or calibrated kinetics mechanism. However, it is not always feasible to obtain concentrations of the numerous hydrocarbon intermediates generated during the combustion of complex hydrocarbon fuels. As a result, validation of complex chemical-kinetics mechanisms using the traditional zero- and one- 
dimensional experimental/numerical studies can be performed only partially. Alternatively, one could include more target flames, such as coaxial nonpremixed [14], Bunsen [15], and centerbody flames [16], and validate the mechanisms for predicting flame shapes, lift-off heights, blowout characteristics, temperature and species distributions, etc. Most of these data can be obtained using measurement techniques ranging from inexpensive (direct photographs) to expensive (laser diagnostics) techniques.

The main reason why researchers are restricting themselves to zero- and one-dimensional data for validating a given chemical-kinetics mechanism stems from modeling limitations. The additional target flames listed above are all of multidimensional in nature and can only be simulated using two- or three-dimensional codes. In fact, calculation of multidimensional flames using detailed chemistries is known since 1960s [17] and the need for understanding combustion phenomena such as flame stability, pollutant formation, and re-ignition have led to the development of CFD codes with detailed chemical kinetics [18-21]. However, due to the fact that computational time increases significantly with the size of the chemical-kinetics mechanism used, CFD code developments are limited to either simple fuels such as hydrogen [22], methane [23], and ethylene [24] that are described with smaller detailed mechanisms (less than 100 species) or to complex fuels such as propane [25], heptane [26], and JP-8 [27] that are described with reduced mechanisms (tens of species). On the other hand, computer hardware technology has advanced significantly during the past decade and desktop cpu with hundreds of cores [28] could become available in the next ten years or so--paving roads for computing multidimensional flames using hundreds of species and thousands of reactions routinely. Recently, Katta and Roquemore [29] have demonstrated feasibility of such simulations through adopting efficient algorithms for faster and error-free calculations with large chemical-kinetics mechanisms. The 
present paper is aimed at 1) demonstrating the current ability to perform detailed chemicalkinetics validation studies using a multidimensional code and 2) to understand the accuracies of the existing mechanisms for n-heptane fuel in simulating various types of combustion phenomenon.

There is a considerable interest in understanding n-heptane combustion as it is treated as a primary reference fuel for octane rating in internal combustion engines. Numerous investigators have developed chemical-kinetic mechanisms describing the oxidation of n-heptane [8-10]. Extensive experimental work has also been performed for validating/developing these detailed mechanisms [30-32]. In the present paper three mechanisms developed by University of California at San Diego, Lawrence Livermore National Laboratory, and National Institute of Standards and Technology are incorporated into a two-dimensional CFD code, UNICORN (UNsteady Ignition and COmbustion using ReactioNs), and investigated their ability to predict chemical and thermal structures of nonpremixed and partially premixed flames, extinction limits, and ignition characteristics.

\section{Mathematical Model:}

UNICORN code $[29,33,34]$ is a time-dependent, axisymmetric mathematical model, which is used for the simulation of unsteady reacting flows. It is capable of performing direct numerical simulations (DNS) and has been developed/improved over several years. Its evolution has been in conjunction with experiments conducted to test its ability to predict ignition, extinction, stability limits, and the dynamic characteristics of nonpremixed and premixed flames of various fuels. It solves for u- and v-momentum equations, continuity, and enthalpy- and speciesconservation equations on a staggered-grid system. The body-force term due to the gravitational field is included in the axial-momentum equation for simulating vertically mounted flames. A 
clustered mesh system is employed to trace the large gradients in flow variables near the flame surface. Three detailed chemical-kinetics models developed for heptane combustion are incorporated. First one is San Diego (SD) mechanism [35]. It consists of 52 species and 544 elementary reactions. The second one is Lawrence Livermore National Laboratory (LLNL) mechanism [36]. It consists of 160 species and 1540 reactions. And the third one is National Institute of Standards and Technology (NIST) mechanism [37]. It consists of 197 species and 2926 reactions. These three mechanisms were chosen as they represent state-of-the-art semidetailed and detailed chemistries for n-heptane combustion. Thermo-physical properties such as enthalpy, viscosity, thermal conductivity, and binary molecular diffusion of all the species are calculated from the polynomial curve fits developed for the temperature range $300-5000 \mathrm{~K}$. Mixture viscosity and thermal conductivity are then estimated using the Wilke and Kee expressions, respectively. Molecular diffusion is assumed to be of the binary-diffusion type, and the diffusion velocity of a species is calculated using Fick's law and the effective-diffusion coefficient of that species in the mixture.

Soot in the flame is simulated as a gaseous species and through the solution of two conservation equations--one for the soot volume fraction and the other for soot number density. Soot nucleation, agglomeration and oxidation processes are modeled following the acetylenebased approach of Lindstedt [38]. A simple radiation model for gaseous species including soot, based on the optically thin-media assumption, is incorporated into the energy equation $[39,40]$. Among all the gaseous species, radiation only from $\mathrm{CH}_{4}, \mathrm{CO}, \mathrm{CO}_{2}, \mathrm{H}_{2} \mathrm{O}$, and soot is considered in the present study.

The finite-difference forms of the momentum equations are obtained using an implicit QUICKEST scheme [34,41], and those of the species and energy equations are obtained using a 
hybrid scheme of upwind and central differencing. At every time step, the pressure field is accurately calculated by solving all the pressure Poisson equations simultaneously and using the LU (Lower and Upper diagonal) matrix-decomposition technique. Different types of boundary conditions such as adiabatic wall, isothermal wall, symmetric surface, outflow, and inflow can be applied to the boundaries of the computational domain [42].

\section{Results and Discussion:}

Multidimensional-flame simulations using UNICORN are performed on a Personal Computer with an AMD Opteron-250 cpu and 2.0 GB of memory. Execution times strongly depend on the number of species considered in the chemical-kinetics model and the grid size. Typical execution times using a mesh of $15 \mathrm{~K}$ nodes and with the SD, LLNL, and NIST mechanisms are 8, 23, and 30 s/time-step, respectively. Steady state solutions are typically obtained in about 4,000 time steps starting from the solution obtained using the global combustion chemistry model. Calculations made with different heptane chemical kinetics models are presented in the following subsections.

\section{Nonpremixed Flame Structure:}

The nonpremixed flame considered for validating the numerical models is a flat flame formed between the opposing jets of pre-vaporized n-heptane and air. Seiser et al. [30] have conducted experiments on this laminar flame and obtained temperature and species measurements along the axis of symmetry (centerline). They performed one-dimensional calculations for the flame structures along the centerline using a shortened version of SD mechanism [30]. In their further studies [31] of these flames they also used LLNL mechanism and a larger version of it having 282 species [36]. The burner was made up of two opposing ducts with inner diameters of 22.2 $\mathrm{mm}$ through which reactants were introduced separately. The distance between the ducts at the 
exits was $10 \mathrm{~mm}$. A known mixture of n-heptane vapor and nitrogen was introduced from the bottom duct while air was introduced from the top duct. The temperatures of the fuel and air jets were 338 and $298 \mathrm{~K}$, respectively. Experiments were conducted for different global strain rates (k) through varying the jet velocities as follows

$$
\text { Strain Rate } k=\frac{2 \mid V_{2}}{L}\left(1+\frac{\left|V_{1}\right|}{\left|V_{2}\right|} \sqrt{\frac{\left|\rho_{1}\right|}{\left|\rho_{2}\right|}}\right)
$$

Here, $V_{1}$ and $V_{2}$ represent the velocities of the fuel and air jets, respectively and $\rho_{1}$ and $\rho_{2}$ represent the densities of the respective jets. $\mathrm{L}$ is the separation distance between the fuel and oxidizer ducts. For model validation purpose the flame established at a moderate strain rate of $150 \mathrm{~s}^{-1}$ is considered. Fuel used for this flame contained 15\% heptane and $85 \%$ nitrogen. Since a two-dimensional simulation of this flat flame requires velocities rather than the strain rate, the fuel and air velocities are determined from densities and using Eq. 1 as 0.342 and 0.375 m/s, respectively. Simulations for the flowfield between the upper and lower ducts are performed using a 301x41 variable grid system, which yielded a uniform spacing of $33 \mu \mathrm{m}$ in the axial direction and expanding spacing with a minimum of $100 \mu \mathrm{m}$ in the radial direction. Calculations are performed using the SD, LLNL, and NIST chemical kinetics models. The three steady state flames obtained are shown in Fig. 1. Temperature distributions between 300 and $1800 \mathrm{~K}$ are plotted using rainbow color scheme. The nonpremixed flame formed between the opposing reactant ducts is nearly flat (planar); however, a close observation indicates that it is slightly curved upward toward air duct. As described earlier, gravitational force in the axial direction is included in the calculations. However, the observed minor curvature to the flame surface did not develop because of gravity. For balancing the momentums of the gases on the two sides of the 
stagnation plane (surface along which the axial velocity component is zero) causes opposing-jet nonpremixed flame to curve toward the air jet. Comparing the temperature distributions shown in Fig. 1 it can be realized that the three mechanisms have resulted in flames that are nearly identical in shapes and sizes.

Temperature and axial-velocity distributions along the centerline across the flame are shown in Fig. 2. While the computed profiles are shown using lines, temperature measurements obtained by Seiser et al. [30] are plotted with solid symbols. Even though the moments of the fuel and air jets were matched, the stagnation point $(\mathrm{U}=0)$ is located $\sim 0.5 \mathrm{~mm}$ away from the midsection $(\mathrm{z}=5 \mathrm{~mm})$ toward the fuel duct. The peak-temperature surface is located $\sim 0.2 \mathrm{~mm}$ away from the midsection toward the air duct, which is also the case in the experiment. All three mechanisms resulted in nearly identical temperature and velocity profiles. Calculated peak temperature values compare well with the measurements. However, flame in the experiment seems to be broader and shifted by $\sim 0.2 \mathrm{~mm}$ toward the air duct. Interestingly, the onedimensional calculations performed by Seiser et al. [30] also resulted in a temperature profile similar to the predictions shown in Fig. 2--suggesting that one-dimensional assumption for this nearly flat, moderately stretched flame is reasonable. Maximum temperature predicted by the NIST mechanism is $\sim 40 \mathrm{~K}$ lower than those obtained with the SD and LLNL mechanisms (Fig. 2). This lower temperature caused less volumetric expansion for the combustion products and less increase to velocity (negative) at $\mathrm{z} \sim 5.8 \mathrm{~mm}$.

Predicted distributions of fuel, oxygen, $\mathrm{H}_{2} \mathrm{O}$, and $\mathrm{CO}_{2}$ along the centerline are shown in Fig. 3 along with the measured ones. Once again, all three chemical-kinetics models predicted nearly the same distributions for these species. Comparisons with experiment are also reasonable, even though, $\mathrm{H}_{2} \mathrm{O}$ concentration was underpredicted. Similar to the differences noted in temperature 
data (Fig. 2), measured species profiles are broader and shifted toward the air duct. It is important to note that measurements for temperature and species concentrations were made using different probes--suggesting that observed differences between the measurements and computations are beyond the experimental errors. However, since both the probes used for the measurements (thermocouple and quartz microprobe [30]) are intrusive type, the uncertainty with regard to the perturbation to the flame in the experiment remains. All three chemicalkinetics mechanisms resulted in the same distributions for the major species shown in Fig 3 even though there are some differences in the temperature predictions (Fig. 2).

Comparisons between the predictions and measurements for some other species such as fuel fragments and radicals are shown in Figs 4 and 5. Distributions of $\mathrm{H}_{2}, \mathrm{CO}$ and $\mathrm{C}_{2} \mathrm{H}_{2}+\mathrm{C}_{2} \mathrm{H}_{4}$ are plotted in Fig. 4 and those of $\mathrm{CH}_{4}, \mathrm{C}_{3} \mathrm{H}_{6}$ and $\mathrm{C}_{2} \mathrm{H}_{6}$ are shown in Fig. 5. In general, models are over predicting the concentrations for these species. Note, similar discrepancies between the measurements and calculations were reported by Seiser et al. [30] in their one-dimensional simulations using CHEMKIN and a shortened version of SD mechanism [43]. While SD and NIST mechanisms in the present two-dimensional simulations predicted concentrations for $\mathrm{H}_{2}$ close to those measured, LLNL mechanism predicted nearly 25\% higher concentration. On the other hand, NIST mechanism's prediction for total concentration of $\mathrm{C}_{2} \mathrm{H}_{2}$ and $\mathrm{C}_{2} \mathrm{H}_{4}$ is lower when compared to the other two mechanisms, but closer when compared with the measurements. Differences in the predictions made by the three mechanisms become more noticeable for the minor species shown in Fig. 5. Over all, the moderately stretched nonpremixed flame was predicted reasonably well with all the three chemical-kinetics mechanisms and no mechanism is found distinctly more accurate than the others. 


\section{$\underline{\text { Strain-Induced Extinction }}$}

Using the opposing-jet burner described in the previous section, Seiser et al. [31] obtained limiting strain rates for extinguishing the nonpremixed flames. Selecting a particular value for the n-heptane-nitrogen ratio in the fuel jet and fixing the stoichiometric mixture fraction $\xi_{s t}$ (defined as $\left[1+\frac{11 Y_{F} W_{O_{2}}}{Y_{O_{2}} W_{F}}\right]^{-1}$, where $W_{F}$ and $W_{O_{2}}$ represent the molecular weights of fuel and oxygen, respectively, and $Y_{F}$ and $Y_{O_{2}}$ represent the mass fractions fuel and oxygen, respectively) at 0.1 , Seiser et al. [31] obtained the ratio between air and nitrogen required in the oxidizer jet. They performed the extinction experiments through varying the fuel and oxidizer jet velocities while allowing only a small change in the flame location by matching the momentums of these jets (Eq. 1). Calculations for these experiments are performed using UNICORN code for assessing the abilities of the SD, LLNL, and NIST mechanisms in predicting the critical extinction strain rates.

Results obtained for the flame with the highest concentrations of fuel and oxygen used in the experiment are shown in Fig. 6. Temperatures of the fuel and oxidizer streams were set as 345 and $298 \mathrm{~K}$, respectively. While the fuel jet was composed of $28.2 \%$ n-heptane and $71.8 \%$ nitrogen by volume, oxidizer jet was composed of $20.5 \%$ oxygen and $79.5 \%$ nitrogen. A separation distance of $10 \mathrm{~mm}$ was maintained between the fuel and oxidizer jets. Calculations for a weakly stretched nonpremixed flame were performed initially after specifying low values for the jet velocities. Stretched flames were then obtained by increasing the fuel and oxidizer jet velocities in steps. Calculations were continued until the flame was extinguished; however, the incremental increases imposed to the velocities were reduced as the flame approached extinction 
conditions. Extinction strain rates for the three mechanisms were obtained through repeating the calculations starting from the weakly stretched flame.

Due to an imbalance between the heat produced in the flame and heat transported away from the flame, opposing-jet flame gets thinner and its maximum temperature decreases as the strain rate (or velocity) is increased. Changes to the flame temperature with strain rate obtained with three chemical-kinetics mechanisms are shown in Fig. 6. Strain rate and temperature obtained for the critical flame (just prior to extinction) are shown with filled circles. Measured extinction strain rate is shown with a hatched rectangle. Significant differences may be found in the flame responses to stretch obtained with the three mechanisms. LLNL mechanism gave the most stable flame with a critical extinction strain rate of $447 \mathrm{~s}^{-1}$. This value compares well with the measured value of $460 \mathrm{~s}^{-1}$. NIST mechanism, which predicted lowest maximum temperatures in a weakly stretched flame (Figs. 2 and 6), predicted flame extinction at a strain rate of $340 \mathrm{~s}^{-1}$. SD mechanism, which predicted highest temperatures in a weakly strained flame (Figs. 2 and 6), predicted flame extinction at a strain rate of $405 \mathrm{~s}^{-1}$. Interestingly, one-dimensional calculations performed by Seiser et al. [31] for this flame using two versions of LLNL mechanism (159species version that is identical to the one used in this study and a 282-species version) yielded extinction strain rates close to $520 \mathrm{~s}^{-1}$, which are $~ 13 \%$ higher than the measured value. The two-dimensional simulations performed in this study using the same mechanism resulted in extinction strain rate that is just $3 \%$ lower than the measurements. As expected, calculations performed for the diluted flames resulted in flame extinction at lower strain rates and the critical values matched well with the measurements. Note that the one-dimensional calculations performed by Seiser et al. [31] also yielded a better agreement between the measurements and simulations for the extinction strain rates for the diluted flames. The better agreement between 
the measurements and calculations made with the two-dimensional model for the largerextinction-strain-rate cases suggests that the errors associated with the one-dimensional assumption for the opposing-jet flame are becoming significant at higher strain rates. Such differences in measured and predicted (one- and two-dimensional) extinction conditions were also noted in the previous studies of opposing-jet partially premixed flames [44].

\section{Autoignition}

Using the previously described opposing-jet flame configuration Seiser et al. [31] performed experiments for the autoignition of heptane fuel. They issued n-heptane-nitrogen mixture from the bottom duct and heated air from the top duct. Autoignition condition was reached by gradually increasing the air temperature. The volume fraction of n-heptane in the fuel jet was kept constant at $15 \%$ while the fuel temperature was maintained at $378 \mathrm{~K}$. Experiments were performed for different strain rates. For validation purpose calculations for this configuration are performed for a strain rate of $400 \mathrm{~s}^{-1}$. This strain rate corresponds to a fuel jet velocity of 0.57 $\mathrm{m} / \mathrm{s}$ and to a $1264-\mathrm{K}$ air jet velocity of $1.2 \mathrm{~m} / \mathrm{s}$. Two-dimensional simulations for autoignition using SD, LLNL, and NIST mechanisms are performed by gradually increasing the air temperature. Since autoignition depends not only on temperature but also on induction time, calculations for this problem must be performed sufficiently long--well beyond the time required for establishing a steady-state flowfield. Temperature distribution obtained for a 1263-K-airflow case is shown in Fig. 7. This is computed using LLNL mechanism and flame was not established as autoignition did not take place. However, when the airflow temperature was increased by another degree to $1264 \mathrm{~K}$ autoignition took place and a steady flame similar to that shown in Fig. 1 was established. 
Heated air mixes with the relatively cold fuel in the region surrounding the stagnation plane. Simultaneous mixing of fuel and oxygen also takes place. A combination of local equivalence ratio, strain rate and temperature determines whether autoignition can take place or not. Therefore, one should not refer air temperature itself to as autoignition temperature and the ability of a chemical kinetics mechanism in predicting autoignition must be assessed through simulating the entire flowfield. Two-dimensional calculations for autoignition of opposing-jet flow are performed using the three chemical-kinetics mechanisms. It is observed that temperature and $\mathrm{OH}$ concentration in the mixing region increase exponentially with air temperature. Therefore, for tracing autoignition process, computed results in the form of maximum temperature and $\mathrm{OH}$ concentration for different air temperatures are shown in Fig. 8. The conditions at which autoignition took place in the calculations are marked with solid circles. The air temperature at which autoignition took place in the experiment is shown with a hatched rectangle. Among the three mechanisms, NIST mechanism is predicting autoignition process closer to the experiment. On the other hand, one-dimensional calculations performed with LLNL mechanism [31] resulted in autoignition when the air temperature was $1237 \mathrm{~K}$. Current twodimensional calculation with the same mechanism predicted (Fig. 8) autoignition at $1264 \mathrm{~K}$. In comparison experiment has suggested 1204-K air temperature for autoignition. However, there is about 50-K error margin associated with the measurements made by Seiser et al. [31]

Simulations for the opposing-jet-autoignition experiments are useful in validating a chemicalkinetics model. However, diffusion of fuel, oxygen and radical species in these simulations influence the ignition process and complicate the analyses of ignition chemistries used in the mechanisms. Traditionally, chemical-kinetics mechanisms are evaluated for their ignition characteristics through the investigation of ignition delay times at different temperatures. 
Calculations for the ignition delay times of a stoichiometric fuel-air mixture at 1-atm pressure are performed using UNICORN code with SD, LLNL, and NIST mechanisms for various temperatures and the results are shown in Fig. 9. These homogeneous ignition calculations are performed in a tube with adiabatic and slip-wall boundary conditions. Results obtained by Seiser et al. [31] for the LLNL mechanism with a zero-d code are also shown in Fig. 9 with filled circles. In general, ignition delay times increased rapidly when the temperature of the mixture is decreased up to $900 \mathrm{~K}$. LLNL mechanism predicted a drop in ignition delay time before raising further for temperatures less than $900 \mathrm{~K}$. UNICORN code has reproduced the ignition characteristics of the LLNL mechanism very well. On the other hand, both the SD and NIST mechanisms yielded monotonically increasing ignition delay times. However, ignition delay times exceeding $10 \mathrm{~ms}$ are of academic interest only and most of the practical combustion systems require temperatures $>1000 \mathrm{~K}$ for ignition purpose. All three mechanisms yielded nearly the same ignition delay times for temperatures $>1000 \mathrm{~K}$. Interestingly, the homogeneousmixture calculations (Fig. 9) performed at $1263 \mathrm{~K}$ resulted 0.81, 0.89, and $0.62 \mathrm{~ms}$ delay times for the SD, LLNL, and NIST mechanisms, respectively, while the opposing-jet-autoignition simulations (Fig. 8) predicted that LLNL mechanism ignites the mixture at lower temperature than the SD mechanism can.

\section{Partially Premixed Flame Structure}

The opposing-jet burner used by Berta et al. [32] for obtaining detailed structures of partially premixed flames consists of upper and lower nozzles and is similar to the burners used in the studies of nonpremixed flames [30,35]. The diameter of each nozzle was $27.38 \mathrm{~mm}$ and the separation distance (L) between them was varied between 10 and $20 \mathrm{~mm}$. Fuel in the form of a mixture of pre-vaporized n-heptane, air and nitrogen was introduced from the bottom nozzle. 
Oxidizer was introduced from the top nozzle. A nitrogen curtain was established through an annular duct surrounding the fuel jet in order to isolate the flames from ambient disturbances. Berta et al. [32] also built an annular duct around the top oxidizer nozzle; however, it was used for venting the gasses flowed into the burner. While the oxidizer was issued at room temperature, the fuel nozzle was heated and its temperature was controlled for maintaining the fuel-containing stream at $400 \mathrm{~K}$. The fuel vaporizer and mixer are described in Ref. 32.

Four partially premixed flames established in this burner are considered for the evaluation of the chemical-kinetics models. Digital images of these flames are shown in the left half of Fig. 10. The weakly stretched weakly premixed flame in 10a was obtained with $k=50 \mathrm{~s}^{-1}, \phi=15.3$, the weakly stretched moderately premixed flame in $10 \mathrm{~b}$ was obtained with $\mathrm{k}=50 \mathrm{~s}^{-1}, \phi=2.5$, the moderately stretched moderately premixed flame in $10 \mathrm{c}$ was obtained with $\mathrm{k}=150 \mathrm{~s}^{-1}, \phi=4.1$ and, finally, the moderately stretched weakly premixed flame in $10 \mathrm{~d}$ was obtained with $\mathrm{k}=150$ $\mathrm{s}^{-1}, \phi=12.6$. A separation of $10 \mathrm{~mm}$ between the fuel and oxidizer nozzles was maintained for all the flames except that in 10b for which the separation distance used was $20 \mathrm{~mm}$. While the images in 10a, 10c, and 10d were taken at the same exposure time, the image in $10 \mathrm{~b}$ was taken at double the exposure time for compensating the lower luminosity of the flame. The following visual observations were made [32] from the flame photographs in Fig. 10:

- An orange-red zone present below the blue layer in 10a

- Green and blue layers are well separated and flame is curved in $10 \mathrm{~b}$

- Green and blue layers are barely separated in 10c

- Merged green and blue layers in 10d. 
- As the stretch is increased and/or the level of premixing is reduced, the premixed reaction zone (green layer) moves closer to the nonpremixed zone (blue layer), i.e., the separation between the two layers decreases.

Two-dimensional simulations for the n-heptane partially premixed flames at different strain rates and equivalence ratios $(\phi)$ are made using UNICORN code and with SD, LLNL, and NIST chemical-kinetics mechanisms. Boundary conditions, including the suction from the outer duct of oxidizer nozzle, were matched to those used in the experiment. Computational results corresponding to the four flames in the left half of Fig. 10 are plotted in the right half. Temperature distributions between the upper and lower nozzles are shown in the left half of the computed flames and soot distributions are shown in the right halves. Note that the flames shown in Fig. 10 obtained with LLNL mechanism and the other two mechanisms also yielded nearly the same flame structures. Shapes of the computed flames matched well with those seen in the experiment. The weakly stretched moderately premixed flame (Fig. 10b) is curved all the way from the center to the edge, while the other three flames are curved only near the edges and yielded flat-flame regions near the center. Simulations made after replacing the suction boundary condition for the oxidizer-side (top) outer duct with an inflow boundary condition similar to that used for the fuel-side (bottom) outer duct yielded flat flames for all the four cases, even though gravitational forces were included in the calculations [45]. This suggests that the flame curvatures seen in Fig. 10 are due to the suction employed in the experiment--but not because of the gravitational force acting on the hot products.

A comparison of calculated temperature and soot distributions of all the flames in Fig. 10 suggest that the weakly stretched moderately premixed flame (Fig. 10b) is the thickest and the weakly stretched weakly premixed flame (Fig. 10a) is the sootiest. These predictions matched 
well with the observations made in experiments. In general, soot surfaces in all these flames are located on the fuel side (bottom) of the peak-temperature surface (red color). However, a careful examination of the computed results reveals that soot surface of the flame in Fig. 10a is significantly away from the peak-temperature surface and this separation decreases gradually as we move through 10a, 10d, 10c, and 10b flames. This is consistent with the digital images from experiments. Soot typically forms on the fuel side of a nonpremixed flame $[46,47]$ and on the products side of a premixed flame [48]. The soot-temperature structure of the partially premixed flame in Fig. 10a exhibits predominantly that of a nonpremixed flame and soot surface moves closer to the peak-temperature surface as in Figs. 10d, 10c, and 10b as the influence of premixed combustion increases. Based on the visual chemiluminescence from $C_{2}$ species and radiation from CO-oxidation species Berta et al. [32] arrived at the similar conclusions on nonpremixed and premixed reactions in these flames.

Computed structure of the weakly stretched weakly premixed flame (Fig. 10a) along the centerline is compared with measurements in Fig. 11. Flame structures obtained with SD, LLNL, and NIST mechanisms are shown with lines and measurements made with thermocouple and gas chromatograph are shown with symbols. Temperature and reactant species $\left(\mathrm{nC}_{7} \mathrm{H}_{16}\right.$ and $\left.\mathrm{O}_{2}\right)$ are compared in Fig. 11a, major product species $\left(\mathrm{H}_{2} \mathrm{O}, \mathrm{CO}_{2}, \mathrm{CO}\right.$, and $\left.\mathrm{H}_{2}\right)$ are compared in Fig. 11b, fuel fragments $\left(\mathrm{CH}_{4}\right.$ and $\left.\mathrm{C}_{2} \mathrm{H}_{2}\right)$ are compared in Fig. 11c, and, finally, ethylene and butene are compared in Fig. 11d. In general, all three chemical-kinetics mechanisms resulted in nearly the same temperature and reactant and major-product-species concentrations, while significant deviations in the predicted concentrations of fuel fragments are observed. Computed temperature profile matched reasonably with that obtained in the experiment (Fig. 11a), even though the measurements show a broader--especially, on the air side--distribution. Note that the 
measurements used intrusive probes, which could perturb the flame and make the distributions broader. Interestingly, LLNL mechanism predicts the premixed combustion ( $\mathrm{z} \sim 3 \mathrm{~mm}$ ) more distinctly compared to the other two mechanisms and agrees better with the measurements. This is a somewhat surprising result considering the lower autoignition temperature (Fig. 8) obtained with NIST mechanism. The structure of a partially premixed flame is characterized by synergistic interactions between the two reaction zones, with the nonpremixed zone supported by the intermediate fuels (i.e., $\mathrm{CO}$ and $\mathrm{H}_{2}$ ) produced in the premixed zone, while the latter is supported by the product species generated in the nonpremixed. These interactions between the premixed and nonpremixed zones make extension of autoignition results to partially premixed flames more difficult or inappropriate. Figures 11c and 11d suggest that SD mechanism predicts $\mathrm{CH}_{4}, \mathrm{C}_{2} \mathrm{H}_{2}$ and $\mathrm{C}_{2} \mathrm{H}_{4}$ concentrations better than the other two mechanisms.

Flame structures obtained with the three mechanisms for the weakly stretched moderately premixed flame are shown in Fig. 12. The strong premixed combustion that is causing the temperature to increase at $\mathrm{z} \sim 7.5 \mathrm{~mm}$ is well captured by all the three mechanisms. However, LLNL mechanism seems to initiate this premixed combustion slightly upstream where velocity would be higher (in opposing-jet flow velocity decreases with distance from jet exit). Like in the previous case (Fig. 11) measured temperature profile is broader than the predicted ones and is shifted toward oxidizer nozzle (Fig. 12a). Major species concentrations except that of $\mathrm{H}_{2} \mathrm{O}$ are well predicted. The one-dimensional calculations performed by Berta et al. [32] using Ranzi's chemical-kinetics model $[49,50]$ also resulted in similar discrepancy in $\mathrm{H}_{2} \mathrm{O}$ predictions. Note that since measured $\mathrm{H}_{2} \mathrm{O}$ values were obtained through mass balancing of all the other measured species including $\mathrm{N}_{2}$, discrepancy between the measurements and calculations for $\mathrm{H}_{2} \mathrm{O}$ reflects integrated discrepancy for all the species. Figures 12c and 12d indicate a good agreement 
between the predictions and measurements for different fuel fragments, even though SD mechanism seems to be performing better compared to the other two mechanisms.

Calculations made for the moderately stretched moderately premixed flame are compared with the measurements in Fig. 13. The agreement among the predictions made with different chemical-kinetics models is the best for this flame. Temperature and major-product-speciesconcentration profiles computed with three mechanisms almost lie on top of each other. However, all three mechanisms failed to predict the temperature rise due to premixed combustion seen in the experiment (Fig. 13a). On the other hand, computed $\mathrm{nC}_{7} \mathrm{H}_{16}, \mathrm{O}_{2}, \mathrm{H}_{2}, \mathrm{CO}$, and $\mathrm{CO}_{2}$ profiles matched well with the measurements. Contrary to the agreement obtained between the predictions and measurements for $\mathrm{CH}_{4}$ and $\mathrm{C}_{2} \mathrm{H}_{2}$ in the previous two flames (Figs. 11c and 12c), these fuel fragments are underpredicted in this moderately stretched moderately premixed flame (Fig. 13c). It is believed that the higher concentrations of $\mathrm{CH}_{4}$ and $\mathrm{C}_{2} \mathrm{H}_{2}$ in the experiment led to the development of the premixed-combustion branch.

Comparisons between the predictions and measurements for the moderately stretched weakly premixed flame are shown in Fig. 14. Reasonable agreement between the measurements and predictions is obtained for this flame. Once again, the major discrepancies are found in the temperature and water comparisons. Measurements clearly show the premixed-combustion branch in the temperature profile (bulge on the fuel side), while none of the mechanisms predicted such a bulge. Instead, all the mechanisms predicted inflections in the temperature profiles on the fuel side. As shown in Fig. 14d, concentrations of minor fuel fragments are reasonably predicted by the three chemical-kinetics mechanisms.

In summary, there are negligible differences between the predictions of the three mechanisms with respect to temperature and major species profiles $\left(\mathrm{nC}_{7} \mathrm{H}_{14}, \mathrm{O}_{2}, \mathrm{CO}_{2}, \mathrm{CO}\right)$. However, there 
are noticeable differences with respect to the intermediate fuel species. For instance, the NIST mechanism predicts less $\mathrm{C}_{2} \mathrm{H}_{4}$, but more $\mathrm{C}_{4} \mathrm{H}_{8}$ compared to the other two mechanisms. The LLNL mechanism predicts more $\mathrm{H}_{2}$, while the SD mechanism predicts less $\mathrm{C}_{2} \mathrm{H}_{2}$ compared to the other mechanisms. LLNL mechanism also consumes $\mathrm{nC}_{7} \mathrm{H}_{14}$ and $\mathrm{O}_{2}$ in the fuel jet faster than the other two mechanisms. All three mechanisms generally reproduced the experimental data in terms of the temperature and major species profiles, although there are some differences with respect to these profiles. Predictions locate the peak flame temperature more toward the fuel jet, by about $0.5-1.0 \mathrm{~mm}$, compared to measurements. The peak $\mathrm{CO}$ mole fractions are underpredicted by all three mechanisms compared to measurements. The differences between the predictions and measurements are more significant with respect to intermediate species $\left(\mathrm{C}_{2} \mathrm{H}_{2}\right.$, $\mathrm{C}_{2} \mathrm{H}_{4}, \mathrm{C}_{4} \mathrm{H}_{8}$ ), indicating a need for further examination of these mechanisms. The predicted rates of production of these species are slower compared to the measured rates, and their peak mole fractions are generally overpredicted by all three mechanisms compared to measurements. Also, not shown here, benzene (PAH species leading to soot production) is included only in the NIST mechanism, and its predictions exhibit reasonable agreement with the measured values, although the location of the peak predicted value is shifted slightly toward the oxidizer jet compared to the measurements.

\section{Conclusions:}

A computational study was performed to elucidate the differences in the combustion characteristics predicted by different detailed chemical kinetics modes for n-heptane fuel. Three chemical kinetics models, namely 1) San Diego (SD) mechanism (52 species and 544 reactions), 2) Lawrence Livermore National Laboratory (LLNL) mechanism (160 species and 1540 reactions), and 3) National Institute of Standards and Technology (NIST) mechanism (197 
species and 2926 reactions) were considered. These mechanisms were incorporated into a timedependent, two-dimensional, computational-fluid-dynamics model known as UNICORN. Abilities of the numerical models in predicting various diffusion-influenced combustion processes were investigated. Predictions were made for the detailed structures of nonpremixed and partially premixed flames, strain-induced extinction and diffusion-controlled autoignition and the results were compared with the available experimental data. Instead of following the traditional approach of simulating opposing-jet flows with one-dimensional models that utilize assumptions on boundary conditions, two-dimensional simulations for the complete flowfields between the opposing nozzles were made.

Flames formed in the opposing jet burners that used momentum-matched velocities for the fuel and oxidizer are found to be nearly flat even under the influence of gravitational forces. Small curvature toward the oxidizer jet establishes as the diffusion flame forms on the air side of the stagnation plane. The three chemical-kinetics mechanisms considered in this study resulted in nearly the same flame locations, shapes and sizes. Flow and chemical structures along the centerline of a moderately stretched nonpremixed flame are simulated reasonably well. Nearly identical velocity, temperature and major species concentrations are obtained with SD, LLNL, and NIST mechanisms, even though the latter mechanism seems to predict slightly lower peak temperature and $\mathrm{CO}$ concentration. Regarding the minor species concentrations none of these three mechanisms gave results consistently comparable to the experiments.

LLNL mechanism predicted the extinction of opposing-jet nonpremixed flame very well. Agreement between the measured and predicted extinction strain rates for a weakly diluted flame was better than that obtained with the same (LLNL) mechanism but with a one-dimensional code. The difference between the extinctions obtained with one- and two-dimensional codes 
vanished in the diluted-flame case for which extinction strain rate was lower. Flames computed with NIST mechanism extinguished at lower strain rates compared to those computed with the other two mechanisms. On the other hand, NIST mechanism predicted ignition of the opposingjet flow at lower oxidizer temperatures, which agrees better with the experiment. The inverse temperature dependence or non-monotonic behavior of ignition delay time with respect to increasing temperature in the LLNL mechanism is absent in the other two mechanisms.

The curved opposing-jet partially premixed flames of Berta et al. [32] have been predicted well by the two-dimensional code. Suction from the outer duct surrounding the upper air nozzle used in the experiment for cooling purpose was found to be responsible for curving the flames. Calculations made without such suction yielded nearly flat flames and it was found that the flame structures along the centerline are not affected by this curvature. All three chemicalkinetics mechanisms computed nearly the same overall shapes for the partially premixed flames although there are some differences in the predicted detailed structures, especially in the premixed-combustion region. LLNL mechanism initiated decomposition of n-heptane by about $0.5 \mathrm{~mm}$ ahead (toward the fuel duct) of the locations where SD and NIST mechanisms have initiated. However, none of these mechanisms predicted the temperature rise associated with premixed combustion in moderately stretched flames. On a positive note, all three mechanisms correctly predicted the exothermic premixed combustion in a partially premixed flame when stretch rate and premixing were weak.

In general, SD, LLNL, and NIST mechanisms predicted nonpremixed and partially premixed n-heptane flames well. Surprisingly, SD mechanism with just one-third of the species used in the other two mechanisms predicted flame structures with nearly the same accuracy. Comparisons with the available experimental data could not suggest which mechanism is better in predicting 
the minor species concentrations. Computations have underpredicted the concentration of water (not measured directly) in both the nonpremixed and partially premixed flames.

\section{Acknowledgments:}

This research was conducted on Air Force Contract F33615-03-D-2329 D03, Mr. Charles Frayne Air Force Program Manager. It is jointly funded by the Fuels and Energy Branch of the Energy/Power/Thermal Division of Air Force Research Laboratory (Program Manager Dr. Tim Edwards) and the Strategic Environmental Research and Development Program (SERDP) (Program Manager Mr. Bruce Sartwell). Their support is greatly appreciated.

\section{References:}

1. Wood, C. P., McDonell, V. G., Smith, R. A., and Samuelsen, G. S., "Development and Application of a Surrogate Distillate Fuel,” Journal of Propulsion and Power, Vol. 5, No. 4, 1989, pp. 399-406.

2. Hahandawala, M. S. P., DeWitt, M. J., Corporan, E., Sidhu, S. S., "Ignition and Emission Characteristics of Surrogate and Practical Jet Fuels,” Energy \& Fuels, Vol. 22, 2008, pp. 3673-3679. Doi:10.1021/ef800303a

3. Pitz, W. J., Cernansky, N. P., Dryer, F. L., Egolfopoulos, F., Farrell, J. T., Friend, D. G., and Pitsch, H "Development of an Experimental Database and Kinetic Models for Surrogate Gasoline Fuels," SAE 2007 Transactions Journal of Passenger Cars - Mechanical Systems, SAE Paper 2007-01-0175, 2007.

4. Colket, M., Edwards, J. T., Williams, S., Cernansky, N. P., Miller, D. L., Egolfopoulos, F. N., Lindstedt, P., Seshadri, K., Dryer, F. L., Law, C. K., Friend, D. G., Lenhert, D. B., Pitsch, H., Sarofim, A., Smooke, M., and Tsang, W., "Development of an Experimental Database and Kinetic Models for Surrogate Jet Fuels," 45th AIAA Aerospace Sciences Meeting and Exhibit, AIAA-2007-0770, Reno, NV, 2007.

5. Smith, G. P., Golden, D. M., Frenklach, M., Moriarty, N. W., Eiteneer, B., Goldenberg, M., Bowman, C. T., Hanson, R. H., Song, S., Gardiner, Jr. W. C., Lissianski, V., and Qin, Z., GRI Mech-3.0: http://www.me.berkeley.edu/grimech/, 1999. 
6. Som, S., Sivaramakrishnan, R., Brezinsky, K., Aggarwal, S. K., "Validation of a Detailed Chemical Kinetic Modeling for the High Pressure Combustion of Methane--Flame and Ignition Characteristics,” 5th US Combustion Meeting, San Diego, CA, March 25-28, 2007.

7. Petersen, E. L., Kalitan, D. M., Simmons, S., Gilles, B., Curran, H. J., Simmie, J. M., “Methane/Propane Oxidation at High Pressures: Experimental and Detailed Chemical Kinetic Modeling,” Proceedings of the Combustion Institute, Vol. 31, 2007, pp. 447-454.

8. Westbrook, C. K., Warnatz, J., and Pitz, W. J., “A Detailed Chemical Kinetic Reaction Mechanism for the Oxidation of Iso-Octane and n-Heptane over an Extended Temperature Range and its Application to Analysis of Engine Knock,” Proceedings of the Combustion Institute, Vol. 22, 1988, pp. 893-901.

9. Lindstedt, P., "Modeling of the Chemical Complexities of Flames," Proceedings of the Combustion Institute, Vol. 27, 1998, pp. 269-285.

10. Chaos, M.; Kazakov, A.; Zhao, Z.; Dryer, F.L.; International Journal of Chemical Kinetics, Vol. 39, No. 7, 2007, pp. 399-414.

11. Rogg, B., “RUN1DL—The Cambridge Universal Laminar Flamelet Computer Code,” in Reduced Kinetic Mechanisms for Applications in Combustion Systems, N. Peters and B. Rogg (Eds), Lecture Notes in Physics m15, Springer-Verlag, Heidelberg, Germany, 1993, pp. 350-351.

12. Lutz, A. E, Kee, R. J., Grcar, J. F., and Rupley, F. M., “OPPDIF: A Fortran program for computing opposed flow diffusion flames,” SAND96-8243, Sandia National Laboratories, Livermore, CA (1996)

13. Kee, R. J., Miller, J. A., and Jefferson, T. H., “CHEMKIN: A general-purpose, problem-independent, transportable, Fortran, chemical kinetic code package,” Technical Report SAND80-8003, Sandia National Laboratories, Livermore, CA, 1980.

14. Smooke, M. D., Lin, P., and Long, M. B., "Computational and Experimental Study of a Laminar Axisymmetric Methane-Air Diffusion Flame,” Proceedings of the Combustion Institute, Vol. 23, 1991, pp. $575-582$.

15. Ibarreta, A. F., and Sung, C-J., "Flame Temperature and Location Measurements of Sooting Premixed Bunsen Flames by Rainbow Schlieren Deflectometry,” Applied Optics, Vol. 44, No. 17, 2005, pp. 35653575. 
16. Roquemore, W. M., Katta, V. R., Stouffer, S. D., Belovich, V., Pawlik, R., Arstingstall, M., Justinger, G., Gord, J. R., Lynch, A., Zelina, J., and Roy, S., "Soot Studies of Laminar Diffusion Flames with Recirculation Zones,” Proceedings of the Combustion Institute, Vol. 32, 2009, pp. 729-736.

17. Ferri, A., “Mixing-Controlled Supersonic Combustion,” Annual Review of Fluid Mechanics, Vol. 5, 1973, pp. 301-338.

18. Takahashi, F., and Katta, V. R., “Chemical Kinetic Structure of the Reaction Kernel of Methane Jet Diffusion Flames,” Combustion Science and Technology, Vol. 155, No. 1, 2000, pp. 243-279.

19. A. D. Anna, J. H. Kent, and R. J. Santoro, "Investigation of species concentration and soot formation in a co-flowing diffusion flame of ethylene,” Combustion Science and Technology, Vol. 179, 2007, pp. 355369.

20. F. Liu, H. Guo, G. J. Smallwood, and O. L. Gulder, “Numerical modeling of soot formation and oxidation in laminar coflow non-smoking and smoking ethylene diffusion flame,” Combustion Theory and Modeling, Vol. 7, 2003, pp. 301-315.

21. Oran, E. S., Weber, J. W. Jr., Stefaniw, E. I., Lefebvre, M. H., “A Numerical Study of a Two-Dimensional $\mathrm{H}_{2}-\mathrm{O}_{2}$-Air Detonation Using a Detailed Chemical Reaction Model,” Combustion and Flame, Vol. 113, 1998, pp. 147-163.

22. Y. Mizobuchi, J. Shinjo, S. Ogawa, and T. Takeno, “A numerical study on the formation of diffusion flame islands in a turbulent hydrogen jet lifted flame,” Proceedings of the Combustion Institute, Vol. 30, 2005, pp. 611-619.

23. C. R. Kaplan and K. Kailasanath, "Flow-field effects on soot formation in normal and inverse methane-air diffusion flames,” Combustion and Flame, Vol. 124, Nos. 1-2, 2001, pp. 275-294

24. B. A. V. Bennett, C. S. Mcenally, L. D. Pfefferle, and M. . Smooke, “Computational and experimental study of axisymmetric coflow partially premixed ethylene/air flames,” Combustion and Flame, Vol. 127, 2001, pp. 2004-2022.

25. D. C. Haworth, B. Cuenot, and T. Poinsot, “Direct Numerical Simulation and Modeling for Lean Stratified Propane-Air Flames,” Combustion and Flame, Vol. 128, 2002, pp. 1-21. 
26. F. Maroteaux, L. Noel, and A. Ahmed, "Numerical Investigations on Methods to Control the Rate of Heat Release of HCCI Combustion Using Reduced n-Heptane with Multidimensional CFD Code,” Combustion Theory and Modeling, Vol. 11, No. 4, 2007, pp. 501-525.

27. Ebrahimi, H., and Malo-Molina, F., "Numerical Investigation of 2-D and 3-D Multitube Pulse Detonation Using $\mathrm{H}_{2}$ and JP8 Fuel,” AIAA-2004-0465, 42 ${ }^{\text {nd }}$ AIAA Aerospace Sciences Meeting and Exhibit, Reno, NV, Jan. 05-09, 2004.

28. Intel Research Report, http://tecresearch.intel.com/articles/Tera-Scale/1421.html

29. Katta, V. R., and Roquemore, W. M., “Calculation of Multidimensional Flames Using Large Chemical Kinetics, AIAA Journal, Vol. 46, No. 7, 2008, pp. 1640-1650.

30. Seiser, R., Truett, L., Trees, D., and Seshadri, K., “Structure and Extinction of Non-Premixed n-Heptane Flames,” Proceedings of the Combustion Institute, Vol. 27, 1998, pp. 649-657.

31. Seiser, R., Pitsch, H., Seshadri, K., Pitz, W. J., and Curran, H. J., “Extinction and Autoignition of nHeptane in Counterflow Configuration,” Proceedings of the Combustion Institute, Vol. 28, 2000, pp. 20292037.

32. Berta, P., Aggarwal, S. K., and Puri, I. K., “An Experimental and Numerical Investigation of n-Heptane/Air Counterflow Partially Premixed Flames and Emission of NOx and PAH Species, Combustion and Flame, Vol. 145, 2006, pp. 740-764.

33. Roquemore, W. M., and Katta, V. R., “Role of flow visualization in the development of UNICORN,” Journal of Visualization 2 (2000) 257-272.

34. Katta, V. R., Goss, L. P., and Roquemore, W. M., "Numerical investigations of transitional $\mathrm{H}_{2} / \mathrm{N}_{2}$ jet diffusion flames,” AIAA Journal 32 (1) (1994) 84.

35. http://www-mae.ucsd.edu/ combustion/cermech/Heptane-Reactions/

36. http://www-cmls.llnl.gov/?url=science_and_technology-chemistry-combustionnc7h16_reduced_mechanism

37. Tsang, W., "Progress in the Development of Combustion Kinetics Databases for Liquid Fuels,” Data Science Journal, Vol. 3, 2004, pp. 1-9. 
38. Lindstedt, R. P., “Simplified Soot Nucleation and Surface Grouth Steps for Non-Premixed Flames," in Soot Formation in Combustion: Mechanisms and Models (H. Bockhorn, Ed.), Springer-Verlag, Heidelberg, 1994, pp. 417-439.

39. Anon, Computational Submodels, International Workshop on Measurements and Computation of Turbulent Nonpremixed Flames. Available at http://www.ca.sandia.gov/TNF/radiation.html.

40. Guo, H., Liu, F., Smallwood, G. J., "Soot and NO Formation in Counterflow Ethylene/Oxygen/Nitrogen Diffusion Flames,” Combustion Theory and Modeling, Vol. 8, 2004, pp. 475-489.

41. Leonard, B. P., “A stable and accurate convective modeling procedure based on quadratic upstream interpolation,” Computational Methods in Applied Mechanical Engineering 19 (1979) 59.

42. Katta, V. R. and Roquemore, W. M., "Numerical studies on trapped-vortex concepts for stable combustion,” Transactions of the ASME: Journal of Engineering for Gas Turbines and Power 120 (April 1998), 60

43. Bollig, M., Pitsch, H., Hewson, J. C., and Seshadri, K., "Reduced n-Heptane Mechanism for Nonpremixed Combustion with Emphasis on Pollutant Relevant Intermediate Species,” Proceedings of the Combustion Institute, Vol. 26, 1996, pp. 729-737.

44. Katta, V. R., Hu, S., Wang, P., Pitz, R. W., Roquemore, W. M., and Gord, J. R., "Investigation of DoubleState Behavior of the Counterflow Premixed Flame System,” Proceedings of the Combustion Institute, Vol. 31, 2007, pp. 1055-1066.

45. Aggarwal, S. K., and Katta, V. R., "Evaluation of Chemical Kinetics Models in Predicting Heptane-Air Partially Premixed Flames,” Paper No. AIAA-2009-5521, 45 ${ }^{\text {th }}$ AIAA/ASME/SAE/ASEE Joint Propulsion Conference and Exhibit, Denver, CO, August 02-05, 2009.

46. McNesby, K. L., Miziolek, A. W., Nguyen, T., Delucia, F. C., Skagga, R. R., and Litzinger, T. A., "Experimental and Computational Studies of Oxidizer and Fuel Side addition of Ethanol to Opposed Flow Air/Ethylene Flames,” Combustion and Flame, Vol. 142, 2005, pp. 413-427.

47. Shaddix, C. R., and Smyth, K. C., "Laser-Induced Incandescence Measurements of Soot Production in Steady and Flickering Methane, Propane, and Ethylene Diffusion Flames,” Combustion and Flame, Vol. 107, 1996, pp. 418-452. 
48. Olson, K. L., Harris, S. J., Weiner, A. M., “Characterization of Polycyclic Aromatic Hydrocarbons on Soot From Premixed Flat Flames,” Combustion Science and Technology, Vol. 51, No. 1-3, 1987, pp. 97-102.

49. Goldaniga, A., Faravelli, T., Ranzi, E., “The Kinetic Modeling of Soot Precursors in a Butadiene Flame,” Combustio and Flame, Vol. 122, No. 3, 2000, pp. 350-358.

50. Ranzi, E., Gaffuri, P., Faravelli, T., Dagaut, P., “A Wide-Range Modeling Study of n-Heptane Oxidation,” Combustion and Flame, Vol. 103, Nos. 1-2, 1995, pp. 91-106. 


\section{List of Figures:}

Fig. 1. Opposing-jet nonpremixed heptane flame simulated using (a) SD, (b) LLNL, and (c) NIST mechanisms. Global strain rate is $150 \mathrm{~s}^{-1}$. Temperature distributions are shown between 300 and $1800 \mathrm{~K}$.

Fig. 2. Distributions of temperature and axial velocity plotted along the centerline. Lines represent flames computed using different chemical kinetics mechanisms and symbols represent measurements of Seiser et al. [30] Global strain rate is $150 \mathrm{~s}^{-1}$.

Fig. 3. Distributions of fuel, oxygen, $\mathrm{H}_{2} \mathrm{O}$, and $\mathrm{CO}_{2}$ plotted along the centerline. Lines represent flames computed using different chemical kinetics mechanisms and symbols represent measurements of Seiser et al. [30] Global strain rate is $150 \mathrm{~s}^{-1}$.

Fig. 4. Distributions of intermediate fuel species $\mathrm{H}_{2}, \mathrm{C}_{2} \mathrm{H}_{2}+\mathrm{C}_{2} \mathrm{H}_{4}$, and $\mathrm{CO}$ plotted along the centerline. Lines represent flames computed using different chemical kinetics mechanisms and symbols represent measurements of Seiser et al. [30] Global strain rate is $150 \mathrm{~s}^{-1}$.

Fig. 5. Distributions of intermediate species $\mathrm{CH}_{4}, \mathrm{C}_{3} \mathrm{H}_{6}$, and $\mathrm{C}_{2} \mathrm{H}_{6}$ plotted along the centerline. Lines represent flames computed using different chemical kinetics mechanisms and symbols represent measurements of Seiser et al. [30] Global strain rate is $150 \mathrm{~s}^{-1}$. 
Fig. 6. Maximum flame temperatures obtained at different strain rates. Solid circles represent extinction conditions.

Fig. 7. Flowfield established between opposing jets of heated air and fuel prior to autoignition. Global strain rate is $400 \mathrm{~s}^{-1}$. Temperature distribution between 300 and $1300 \mathrm{~K}$ and $\mathrm{OH}$ concentration between 0 and 60 ppm are shown in the left and right halves, respectively.

Fig. 8. Maxima in temperature and $\mathrm{OH}$ concentration developed between the opposing jets of heated fuel and air jets for different air-jet temperatures. Solid circles represent autoignition conditions.

Fig. 9. Ignition delay times of homogeneous stoichiometric mixture of n-heptane vapor and air at different temperatures.

Fig. 10. Actual and simulated opposing-jet partially premixed flames. Direct photographs and simulations made with LLNL mechanism are show in the left and right halves, respectively for (a) weakly stretched weakly premixed flame, (b) weakly stretched moderately premixed flame, (c) moderately stretched moderately premixed flame, and (d) moderately stretched weakly premixed flame. Distributions of temperature are plotted between 300 and $2100 \mathrm{~K}$ in the left halves and distributions of soot between 0 and $1 \mathrm{ppm}$ are shown in the right halves of the computational flames. 
Fig. 11. Comparisons of the structures of the weakly stretched weakly premixed flame simulated using different chemical-kinetics mechanisms (lines) with those measured (symbols). Profiles of (a) temperature and reactant species, (b) major product species, (c) methane and acetylene, and (d) ethylene and butene are compared.

Fig. 12. Comparisons of the structures of the weakly stretched moderately premixed flame simulated using different chemical-kinetics mechanisms (lines) with those measured (symbols). Profiles of (a) temperature and reactant species, (b) major product species, (c) methane and acetylene, and (d) ethylene and butene are compared.

Fig. 13. Comparisons of the structures of the moderately stretched moderately premixed flame simulated using different chemical-kinetics mechanisms (lines) with those measured (symbols). Profiles of (a) temperature and reactant species, (b) major product species, (c) methane and acetylene, and (d) ethylene and butene are compared.

Fig. 14. Comparisons of the structures of the moderately stretched weakly premixed flame simulated using different chemical-kinetics mechanisms (lines) with those measured (symbols). Profiles of (a) temperature and reactant species, (b) major product species, (c) methane and acetylene, and (d) ethylene and butene are compared. 
(a)

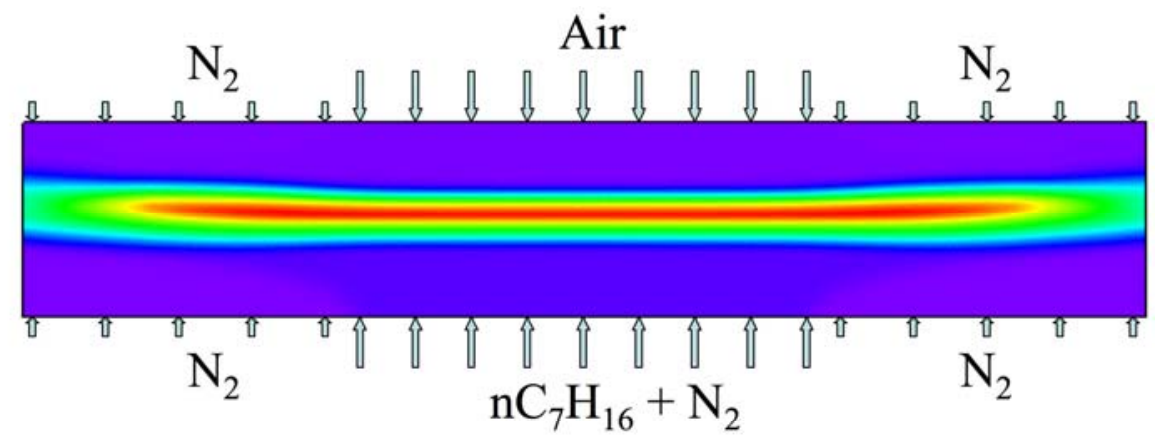

(b)

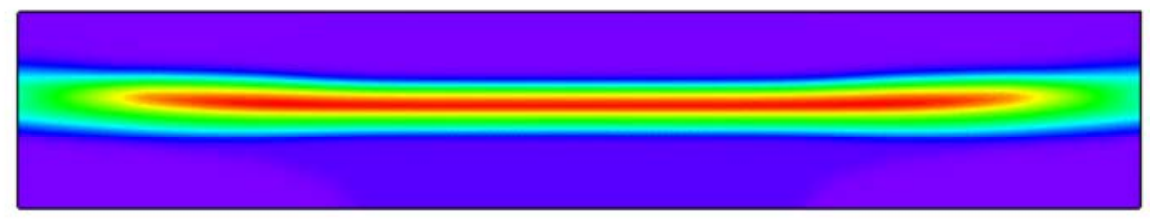

(c)

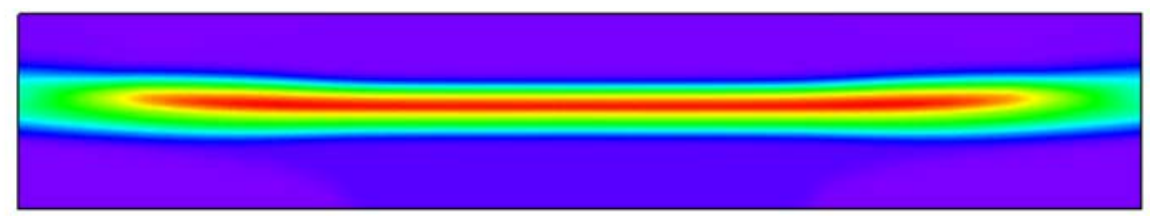

Fig. 1. Opposing-jet nonpremixed heptane flame simulated using (a) SD, (b) LLN, and (c) NIST mechanisms. Global strain rate is $150 \mathrm{~s}^{-1}$. Temperature distributions are shown between 300 and $1800 \mathrm{~K}$. 


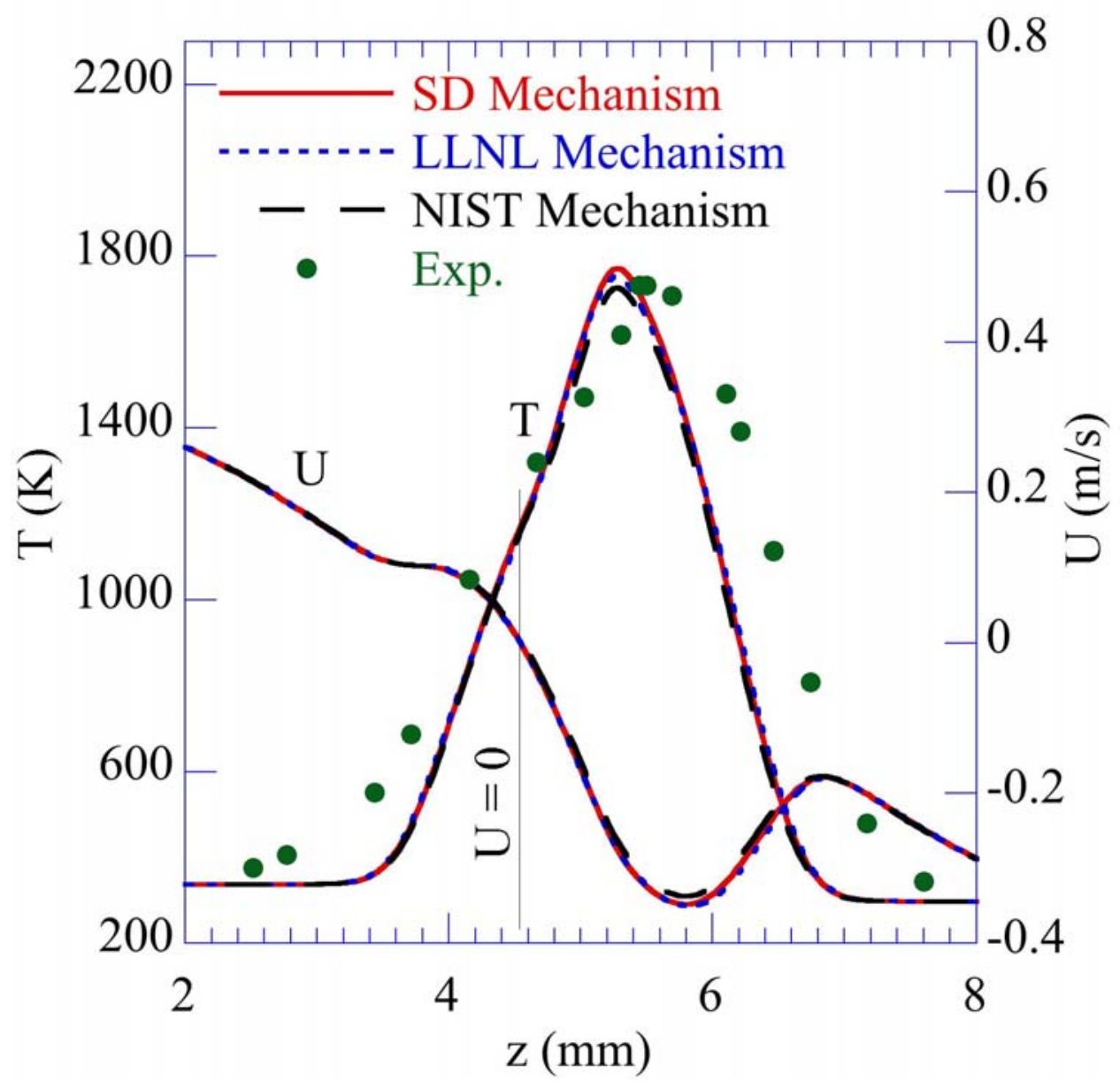

Fig. 2. Distributions of temperature and axial velocity plotted along the centerline. Lines represent flames computed using different chemical kinetics mechanisms and symbols represent measurements of Seiser et al. [30] Global strain rate is $150 \mathrm{~s}^{-1}$. 


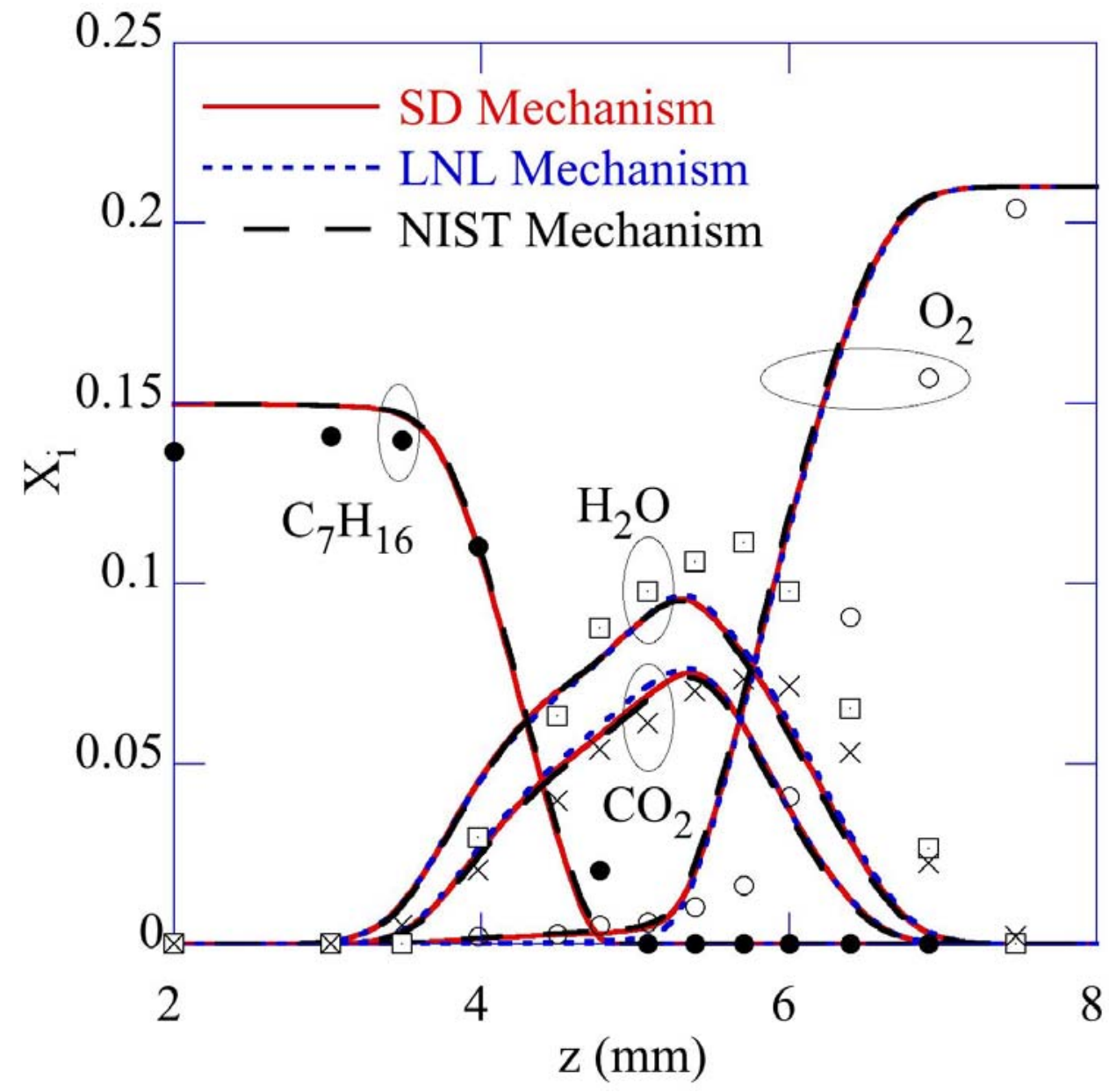

Fig. 3. Distributions of fuel, oxygen, $\mathrm{H}_{2} \mathrm{O}$, and $\mathrm{CO}_{2}$ plotted along the centerline. Lines represent flames computed using different chemical kinetics mechanisms and symbols represent measurements of Seiser et al. [30] Global strain rate is $150 \mathrm{~s}^{-1}$. 


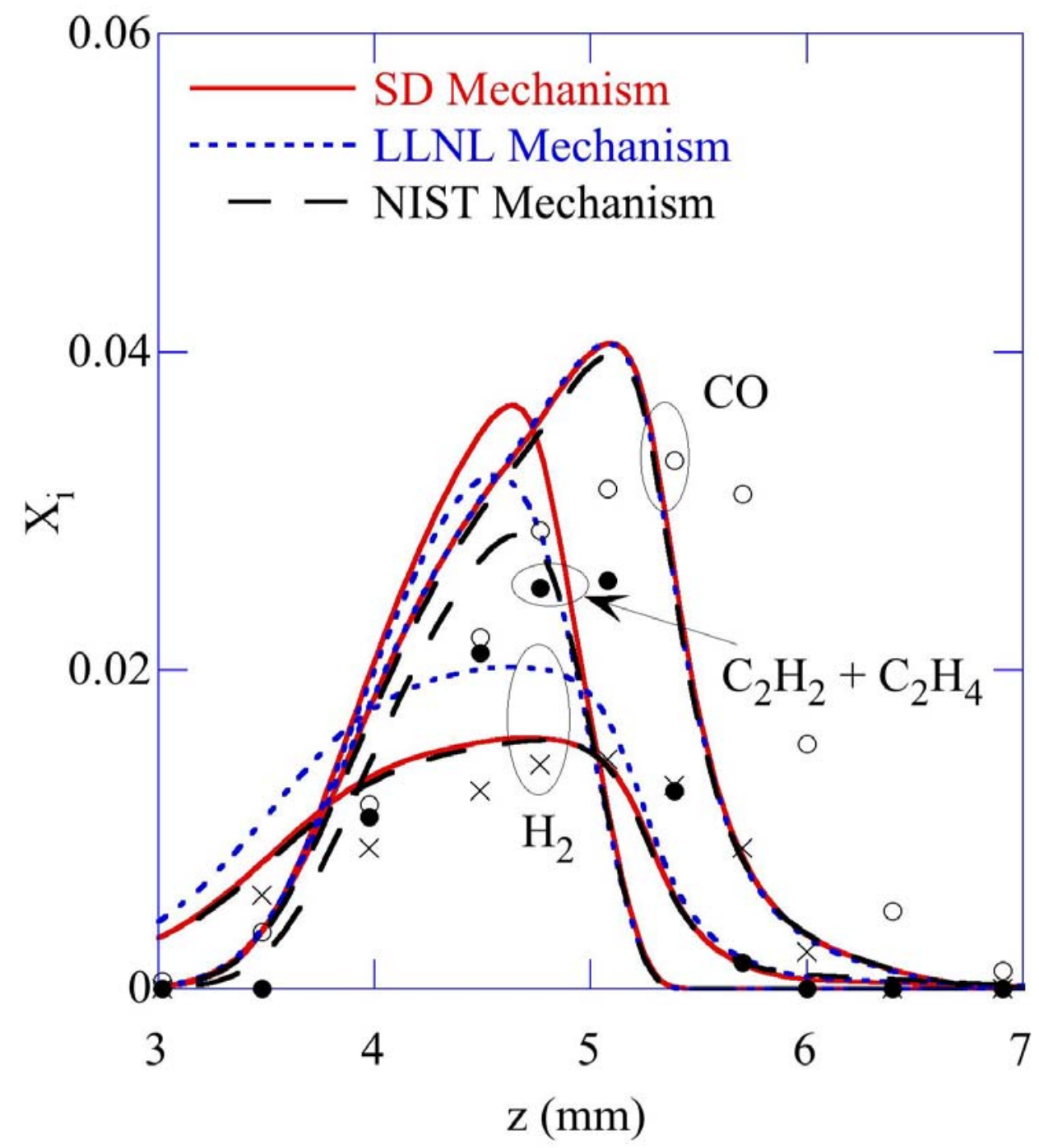

Fig. 4. Distributions of intermediate fuel species $\mathrm{H}_{2}, \mathrm{C}_{2} \mathrm{H}_{2}+\mathrm{C}_{2} \mathrm{H}_{4}$, and $\mathrm{CO}$ plotted along the centerline. Lines represent flames computed using different chemical kinetics mechanisms and symbols represent measurements of Seiser et al. [30] Global strain rate is $150 \mathrm{~s}^{-1}$. 


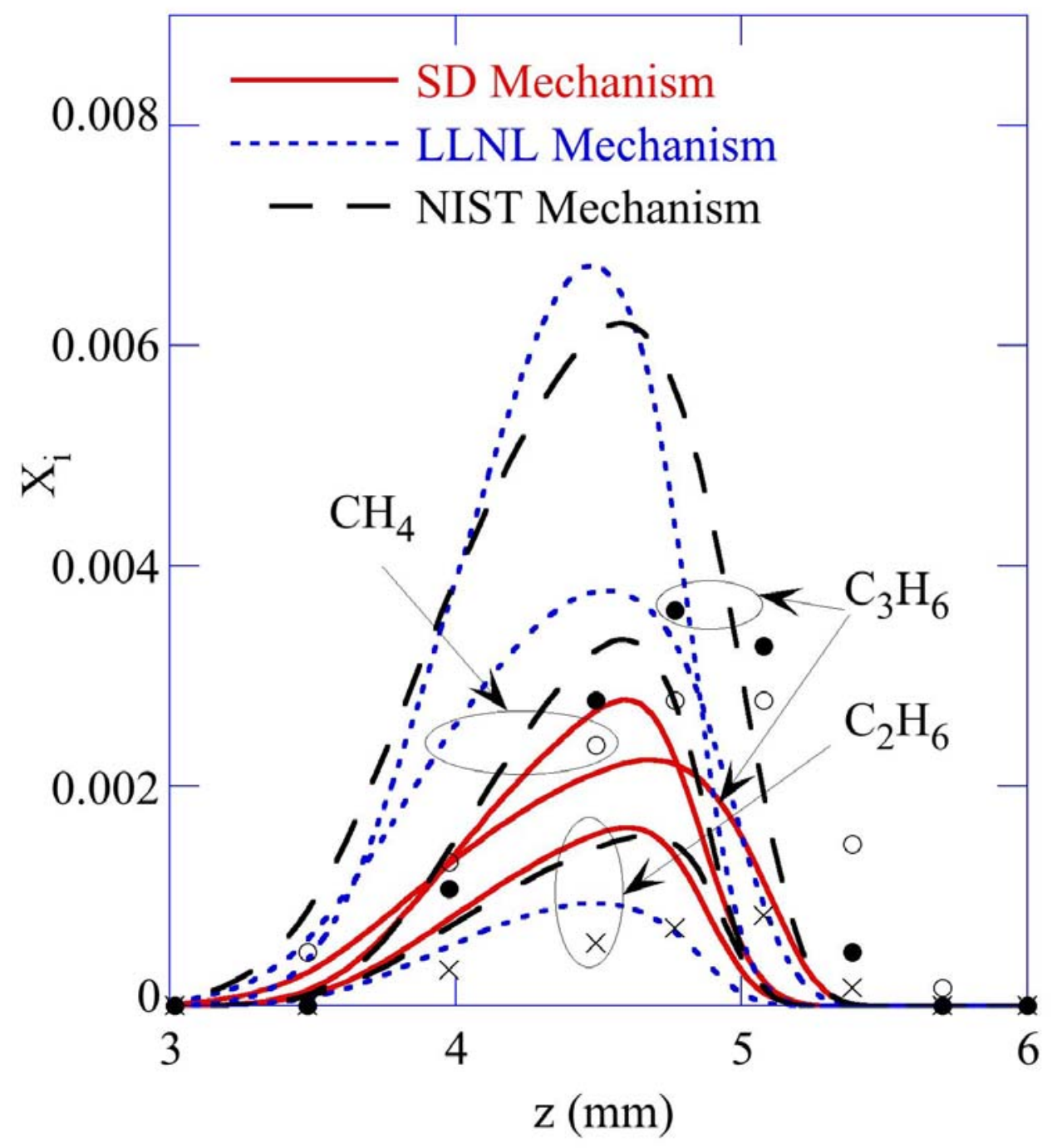

Fig. 5. Distributions of intermediate species $\mathrm{CH}_{4}, \mathrm{C}_{3} \mathrm{H}_{6}$, and $\mathrm{C}_{2} \mathrm{H}_{6}$ plotted along the centerline. Lines represent flames computed using different chemical kinetics mechanisms and symbols represent measurements of Seiser et al. [30] Global strain rate is $150 \mathrm{~s}^{-1}$. 


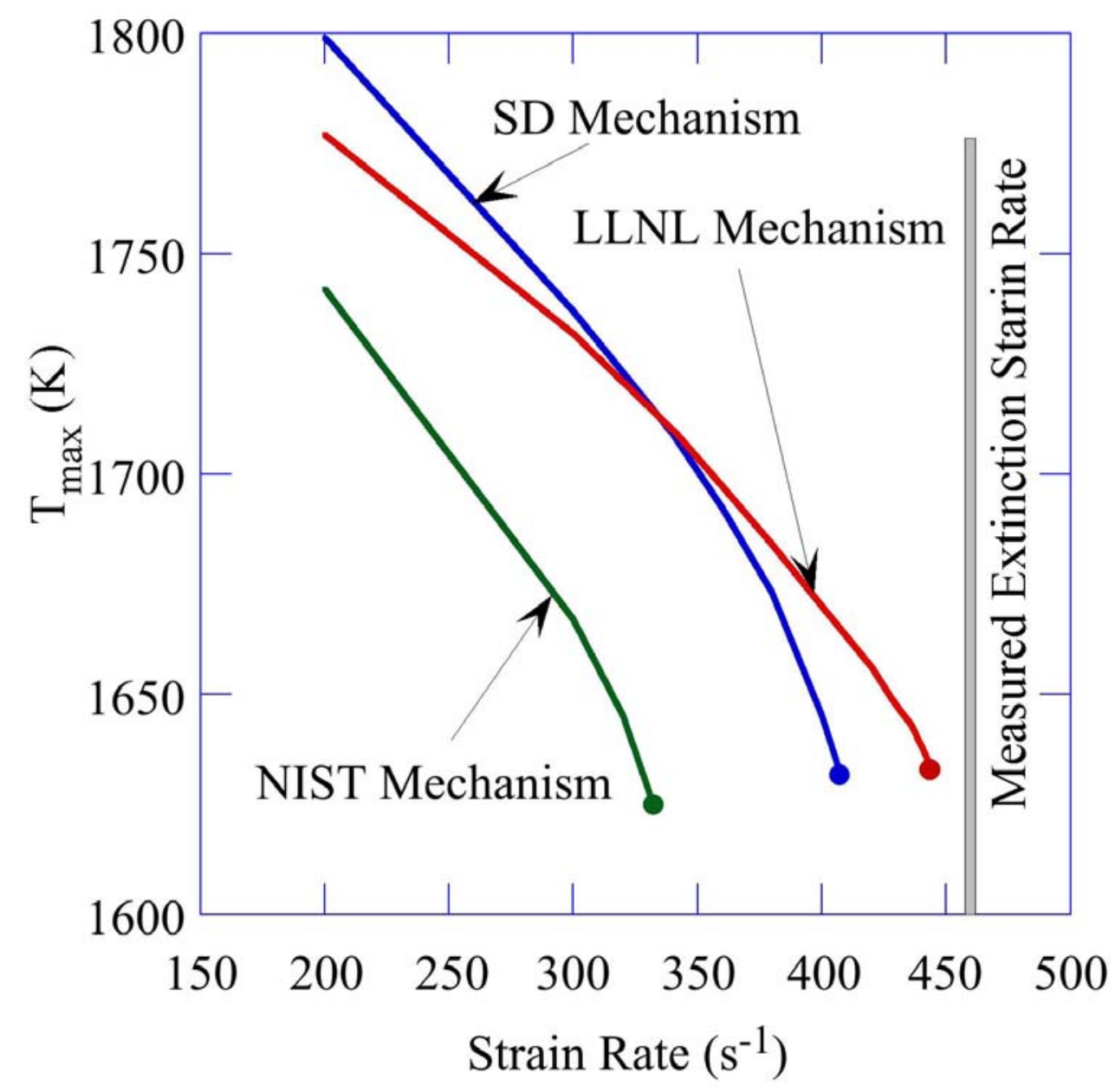

Fig. 6. Maximum flame temperatures obtained at different strain rates. Solid circles represent extinction conditions. 


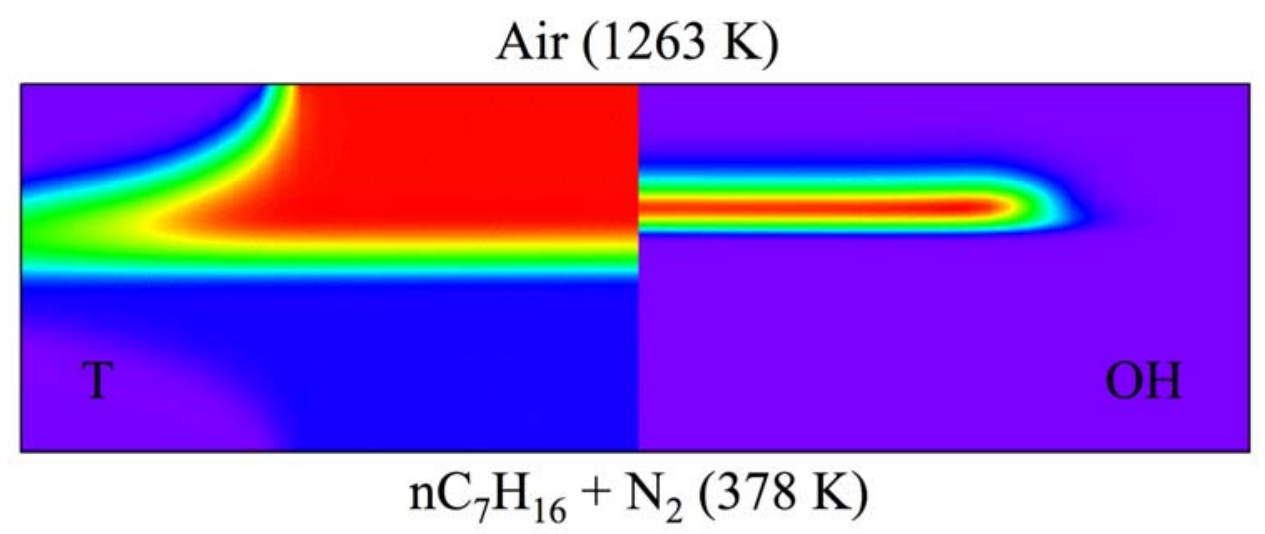

Fig. 7. Flowfield established between opposing jets of heated air and fuel prior to autoignition. Global strain rate is $400 \mathrm{~s}^{-1}$. Temperature distribution between 300 and $1300 \mathrm{~K}$ and $\mathrm{OH}$ concentration between 0 and $60 \mathrm{ppm}$ are shown in the left and right halves, respectively. 


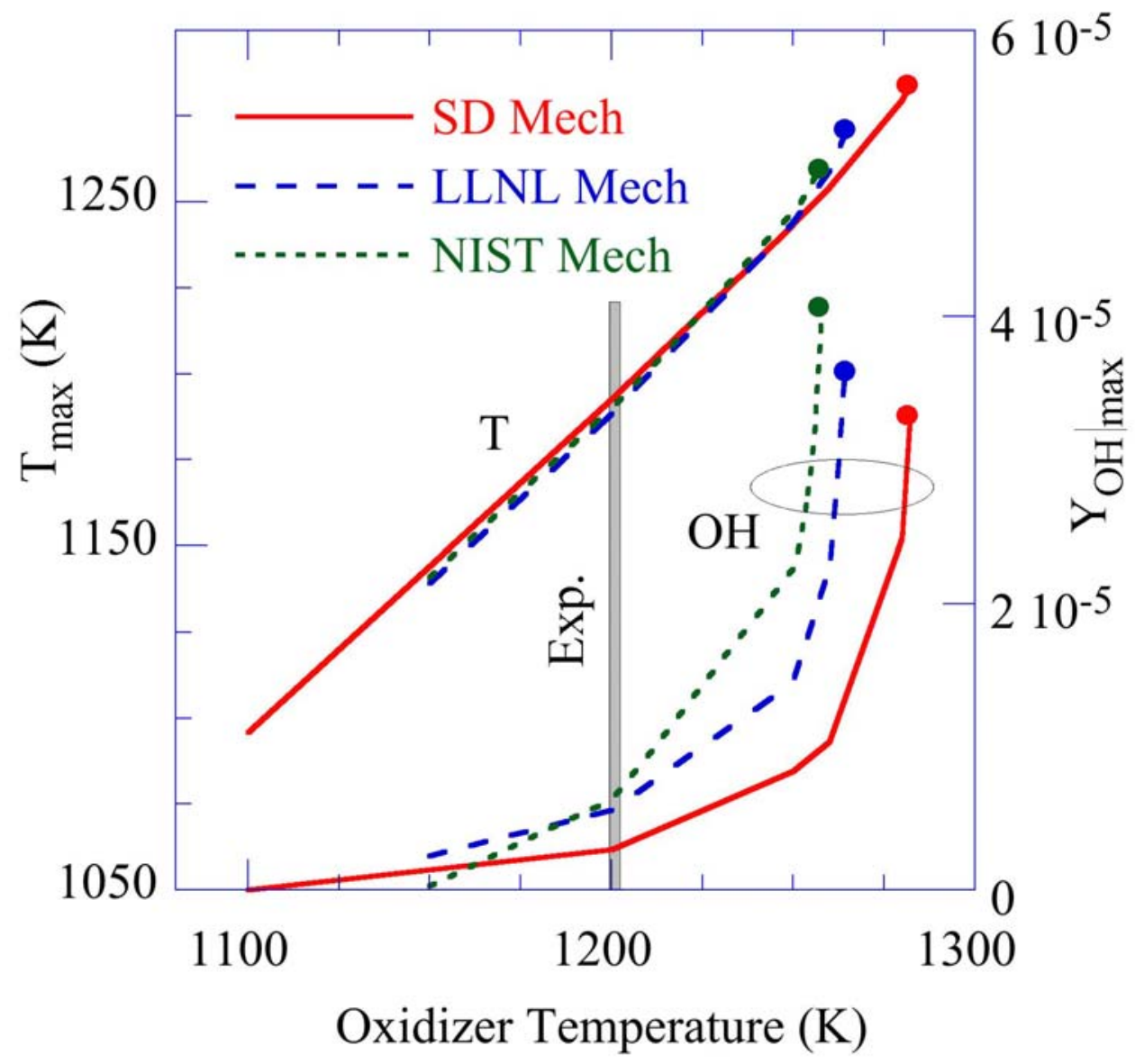

Fig. 8. Maxima in temperature and $\mathrm{OH}$ concentration developed between the opposing jets of heated fuel and air jets for different air-jet temperatures. Solid circles represent autoignition conditions. 


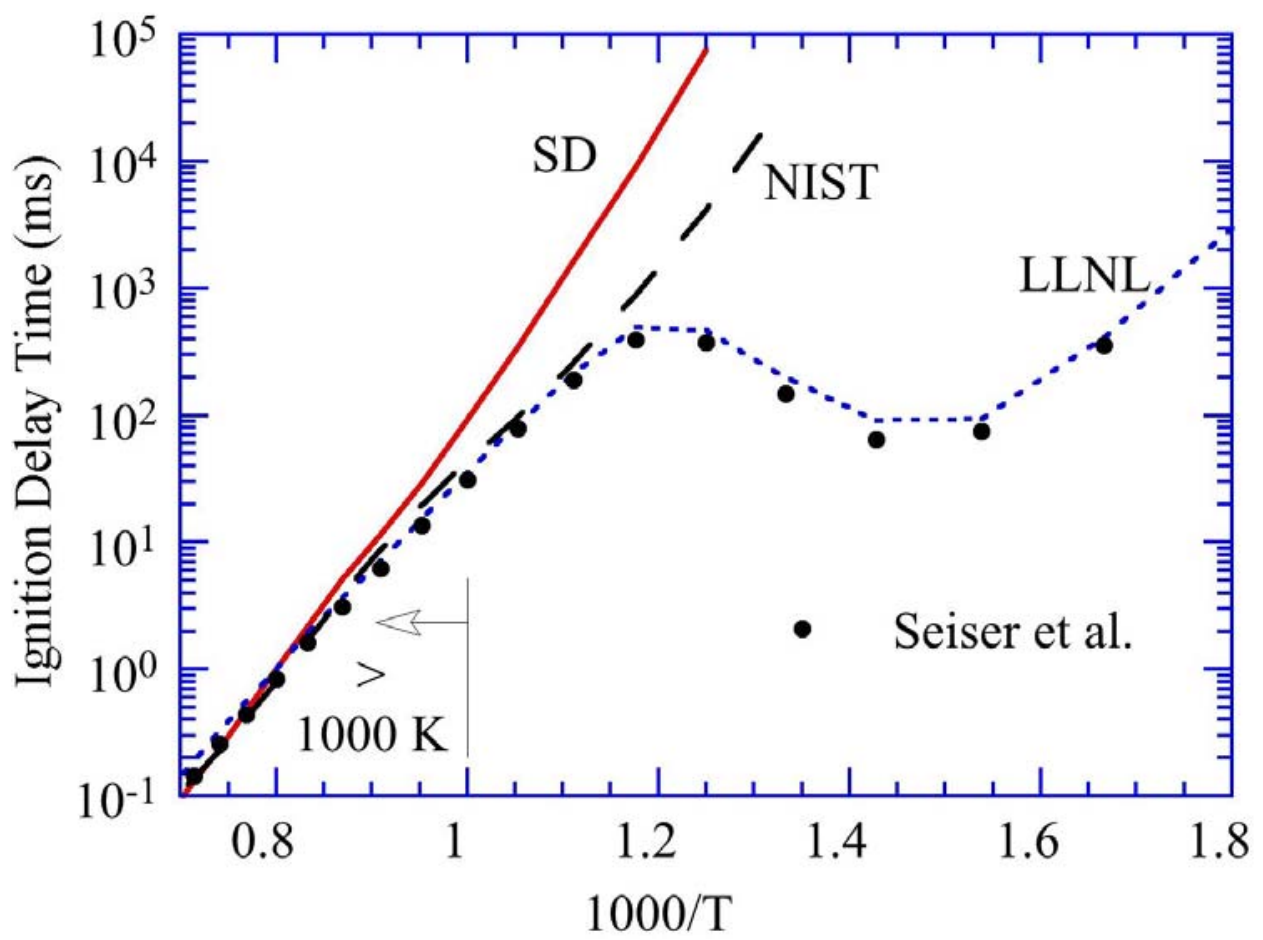

Fig. 9. Ignition delay time in homogeneous, stoichiometric mixture of n-heptane vapor and air at different temperatures. 
(a)
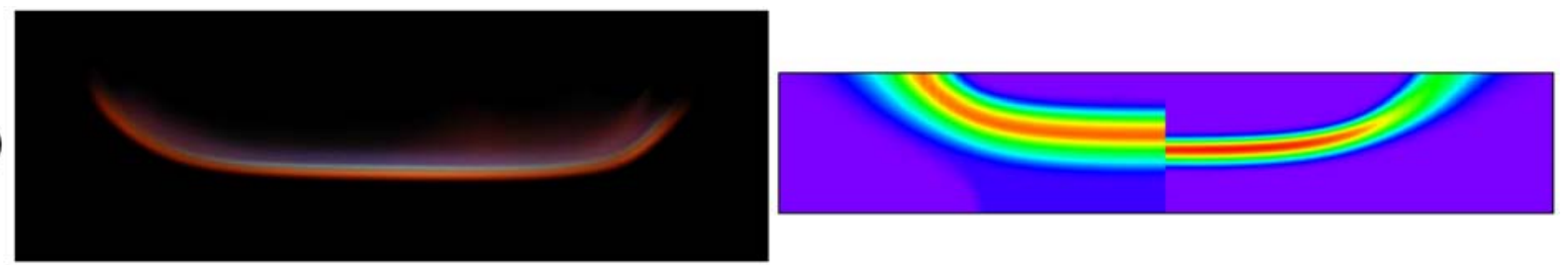

(b)
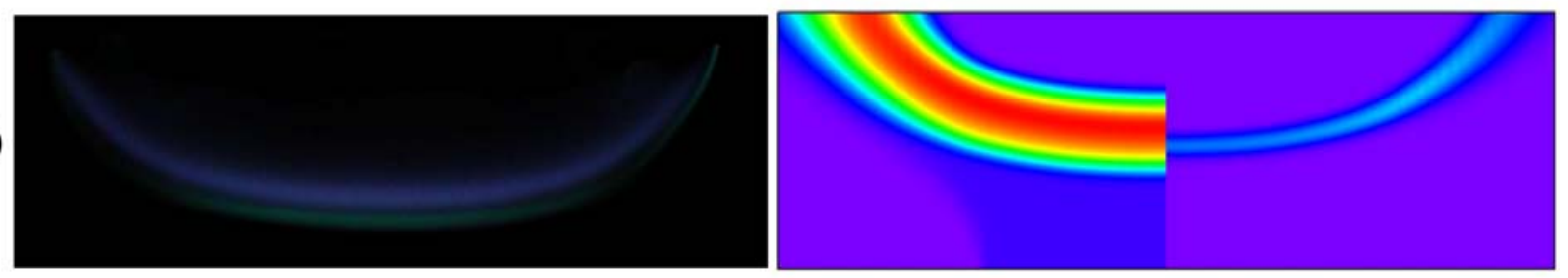

(c)
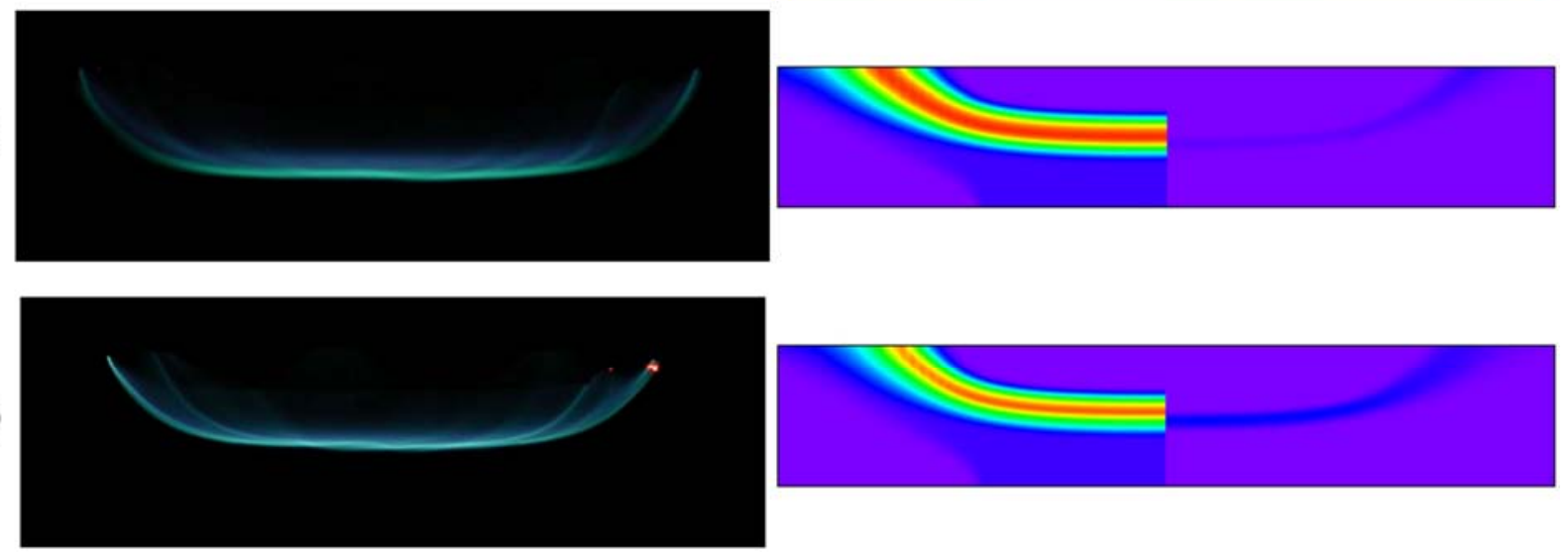

Fig. 10. Actual and simulated opposing-jet partially premixed flames. Direct photographs and simulations made with LLNL mechanism are show in the left and right halves, respectively for (a) weakly stretched weakly premixed flame, (b) weakly stretched moderately premixed flame, (c) moderately stretched moderately premixed flame, and (d) moderately stretched weakly premixed flame. Distributions of temperature are plotted between 300 and $2100 \mathrm{~K}$ in the left halves and distributions of soot between 0 and $1 \mathrm{ppm}$ are shown in the right halves of the computational flames. 

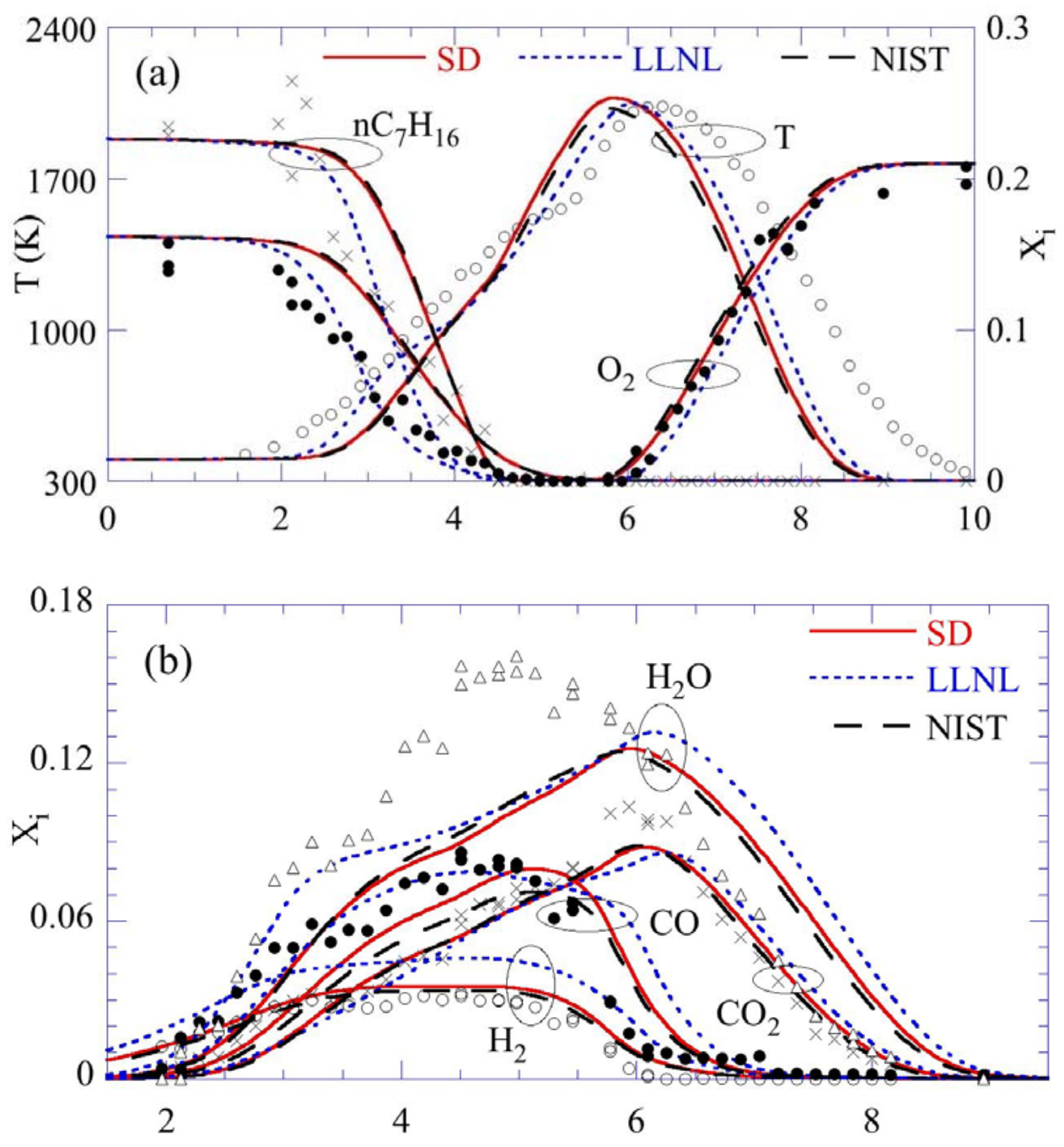

Fig. 11 (Continued in the next page) 

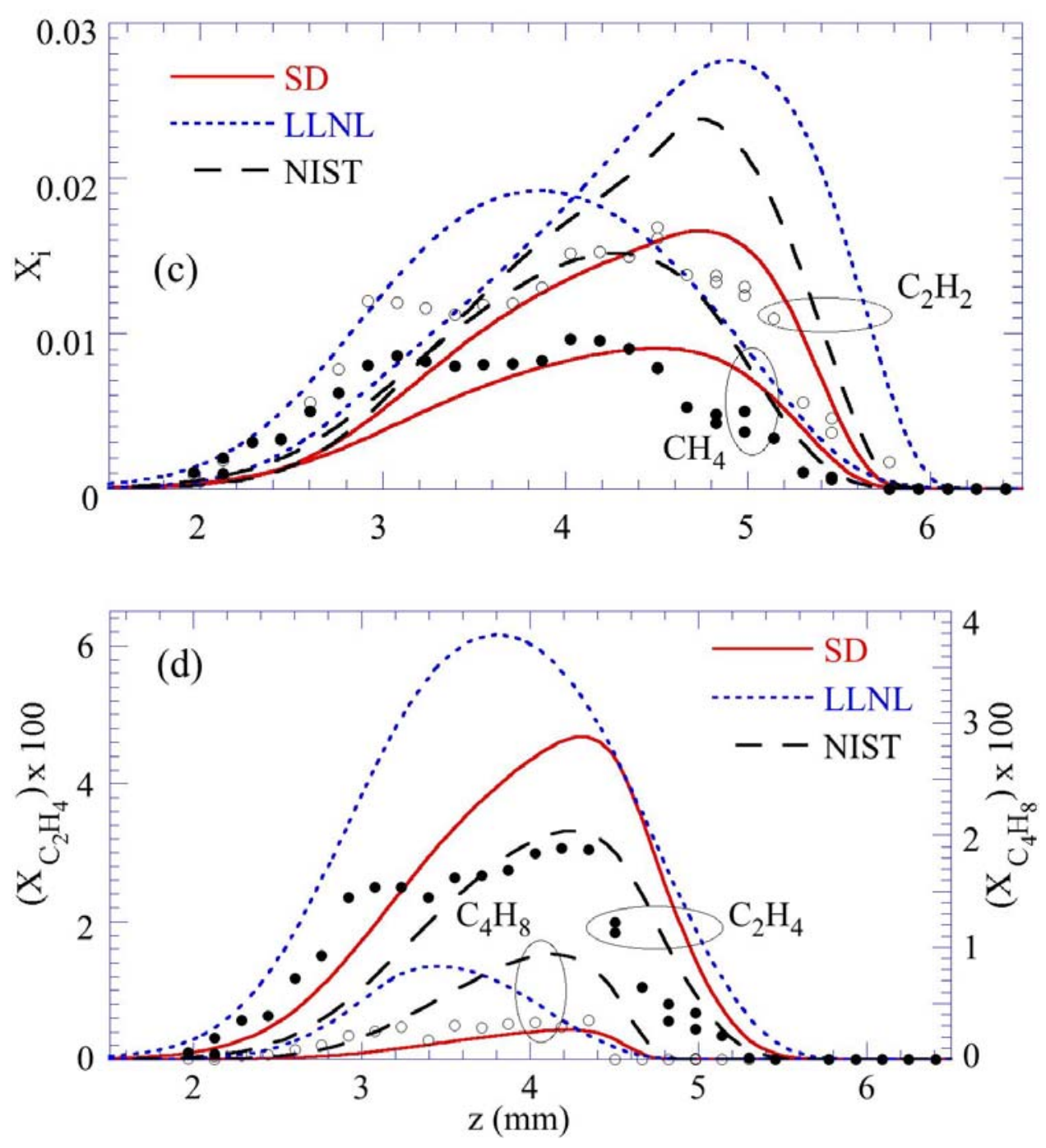

Fig. 11. Comparisons of the structures of the weakly stretched weakly premixed flame simulated using different chemical-kinetics mechanisms (lines) with those measured (symbols). Profiles of (a) temperature and reactant species, (b) major product species, (c) methane and acetylene, and (d) ethylene and butene are compared. 

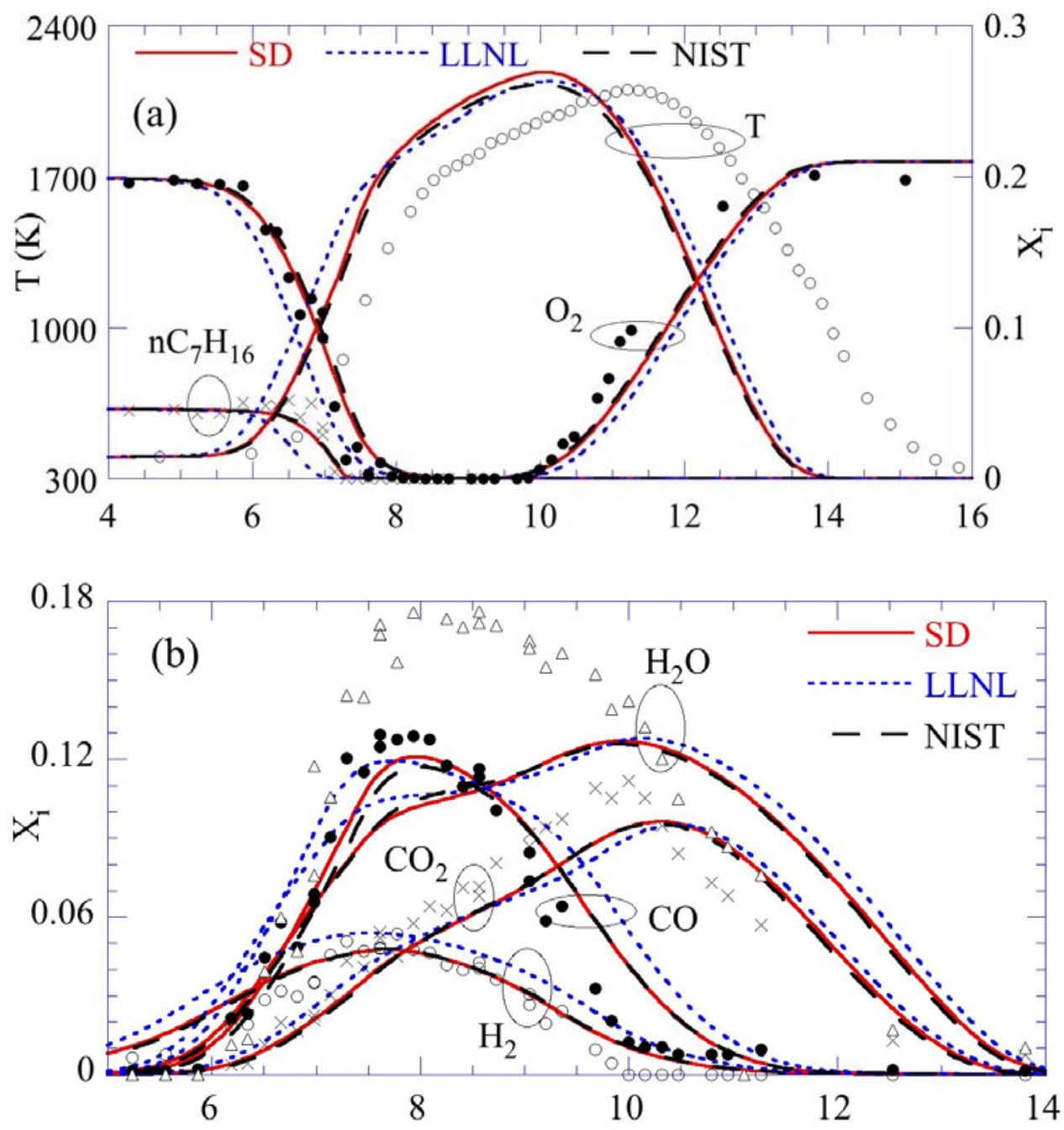

Fig. 12 (Continued in the next page) 

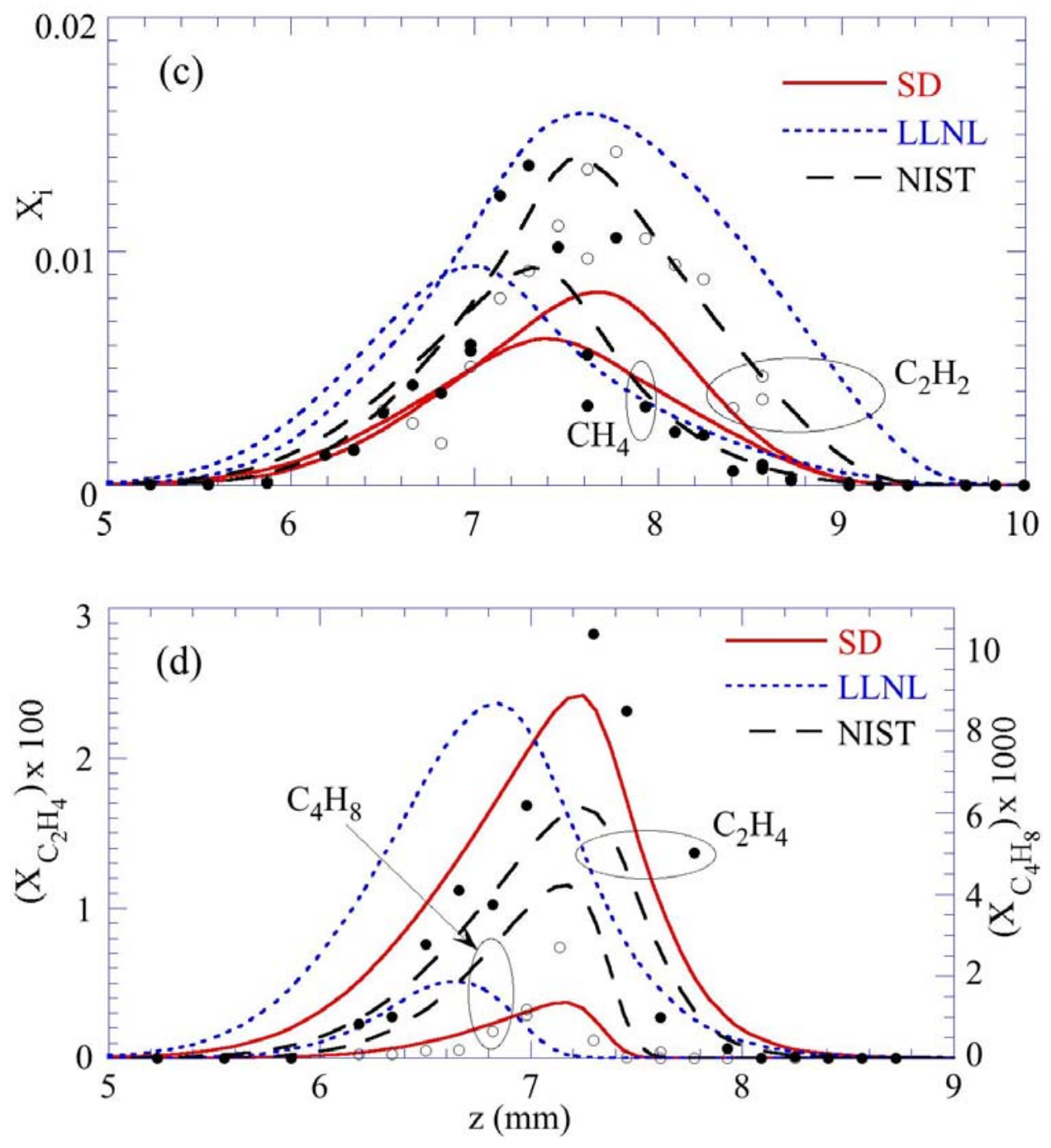

Fig. 12. Comparisons of the structures of the weakly stretched moderately premixed flame simulated using different chemical-kinetics mechanisms (lines) with those measured (symbols). Profiles of (a) temperature and reactant species, (b) major product species, (c) methane and acetylene, and (d) ethylene and butene are compared. 

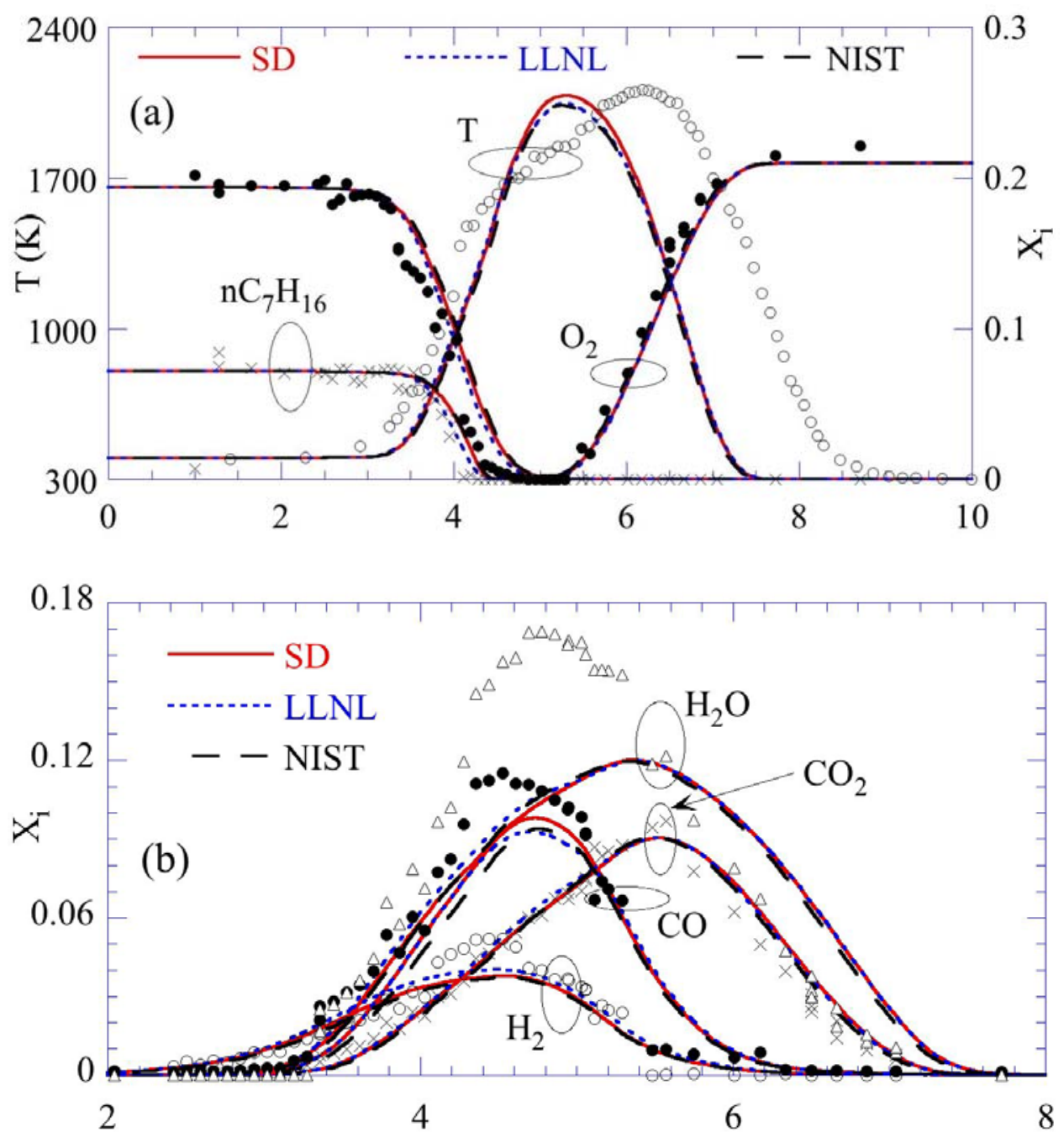

Fig. 13 (Continued in the next page) 

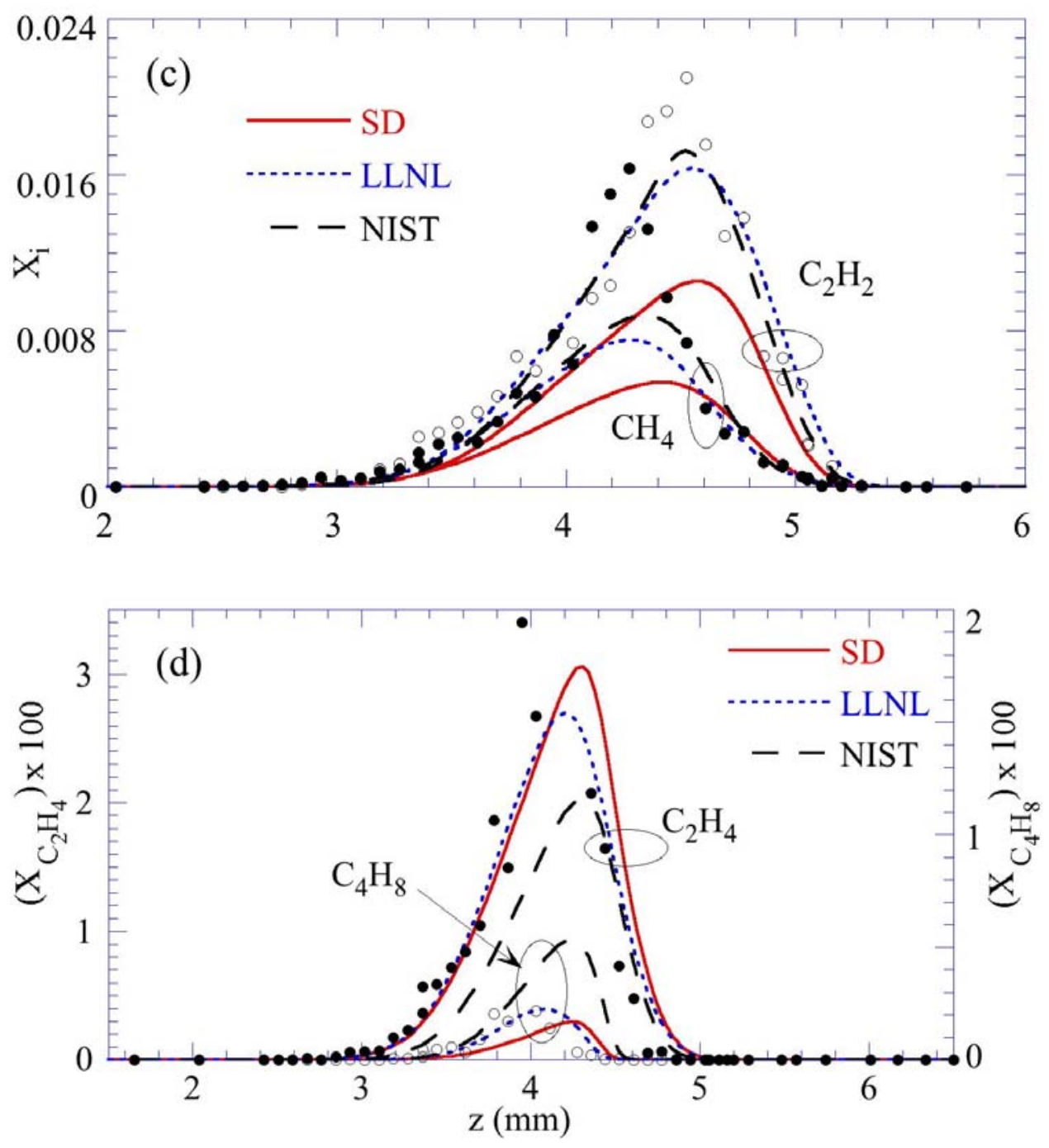

Fig. 13. Comparisons of the structures of the moderately stretched moderately premixed flame simulated using different chemical-kinetics mechanisms (lines) with those measured (symbols). Profiles of (a) temperature and reactant species, (b) major product species, (c) methane and acetylene, and (d) ethylene and butene are compared. 

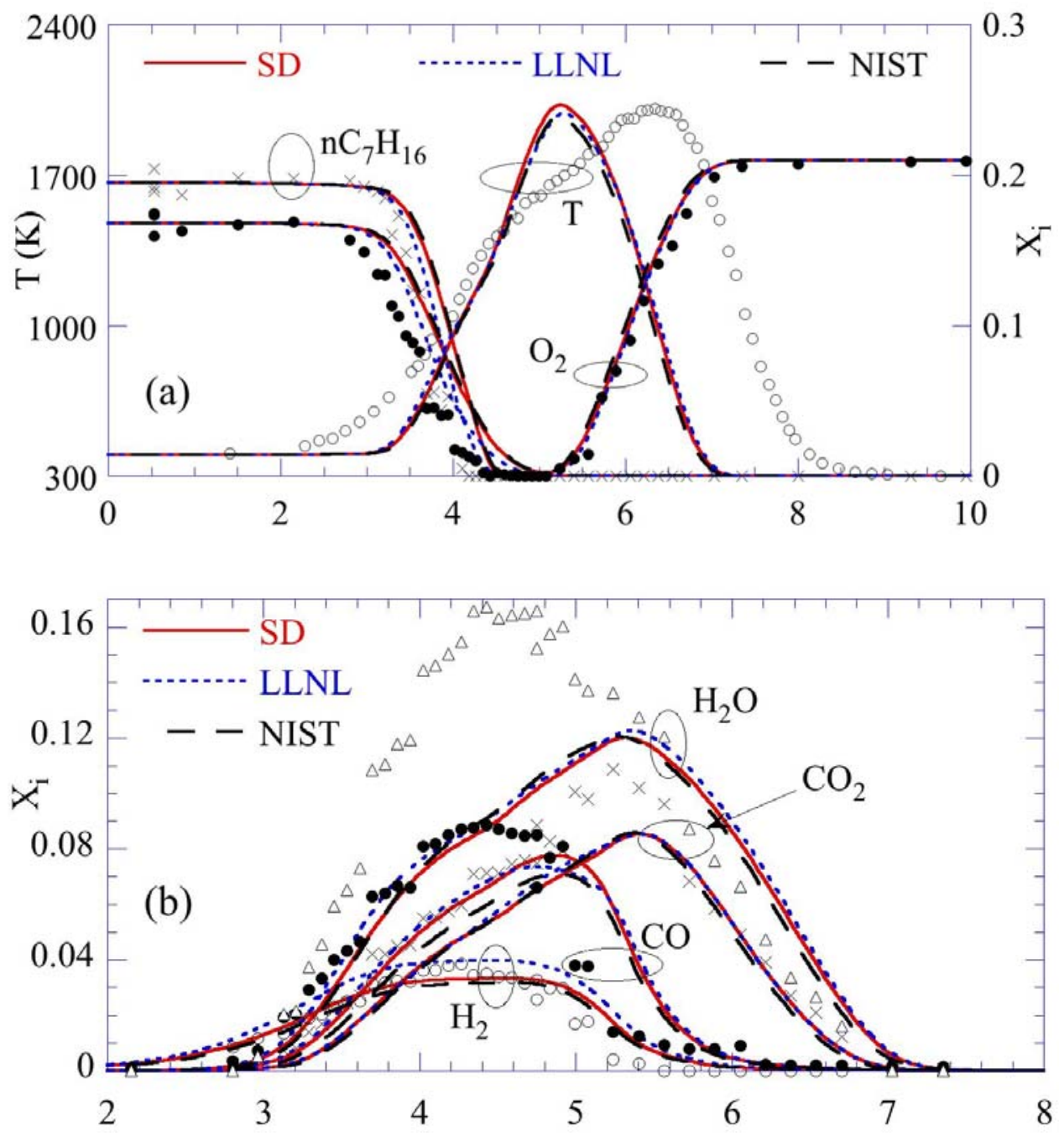

Fig. 14 (Continued in the next page) 

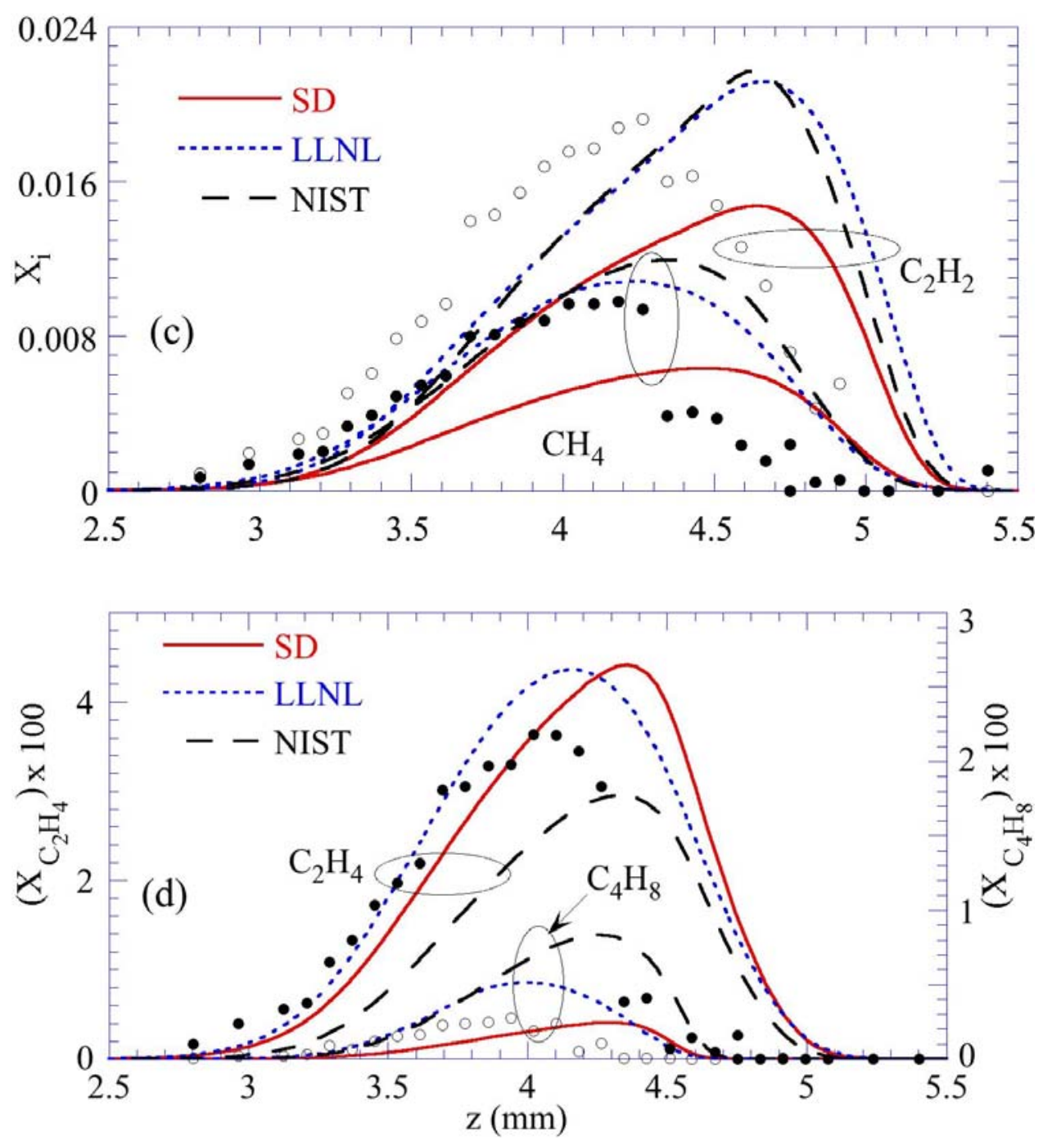

Fig. 14. Comparisons of the structures of the moderately stretched weakly premixed flame simulated using different chemical-kinetics mechanisms (lines) with those measured (symbols). Profiles of (a) temperature and reactant species, (b) major product species, (c) methane and acetylene, and (d) ethylene and butene are compared. 